\title{
Estratificação Educacional no Brasil do Século XXI
}

\section{Arnaldo Mont'Alvão}

Doutorando em Sociologia do Programa de Pós-Graduação em Sociologia, da Universidade Federal de Minas Gerais (UFMG). Mobilidade social, estratificação educacional, sociologia urbana, migrações são suas áreas de interesse. Belo Horizonte, MG, Brasil (e-mail: montalvao@ufmg.br)

\section{INTRODUÇÃO}

L stratificação educacional refere-se à relação entre as origens so1 ciais e o alcance educacional dos estudantes. Quanto mais mobilidade social permite uma sociedade, mais aberta e possivelmente democrática ela é, e assim um sistema escolar é mais aberto ou democrático quanto menor for a correlação entre a origem social do aluno e seu desempenho durante o processo escolar (Silva, 2003).

A importância da escola como mecanismo de mobilidade é destacada pela teoria da modernização (Parsons, 1970; Treiman, 1970), que projeta a educação como principal mecanismo de equalização das oportunidades sociais, capaz de superar as velhas e rígidas estruturas de transmissão direta de status entre gerações.

Visões menos otimistas sobre o papel da escola na sociedade também têm recebido destaque no campo de pesquisas educacionais. As principais são as teorias reprodutivistas (Bowles e Gintes, 1976; Bourdieu e Passeron, 1977), que percebem a educação na sociedade moderna como um instrumento de reprodução e dominação social, usado pelas classes dominantes para transmitirem seu capital cultural e assegurar que seus filhos atinjam ao menos posições sociais semelhantes às suas.

DADOS - Revista de Ciências Sociais, Rio de Janeiro, vol. 54, n-2, 2011, pp. 389 a 430. 
Modelos analíticos variados - modelo de seletividade diferencial (Mare, 1980, 1981), hipótese da desigualdade maximamente mantida (Raftery e Hout, 1993), hipótese da desigualdade efetivamente mantida (Lucas, 2001) etc. - instigados pelo debate entre estas correntes, têm investigado, ao longo das últimas décadas, e para uma variedade considerável de países, a relação entre expansão escolar e estratificação educacional, apontando relações mais complexas do que, a princípio, as teorias anteriores seriam capazes de explicar no mundo contemporâneo.

Este texto apresenta, em primeiro lugar, uma síntese do processo de expansão educacional no Brasil, para então discutir as principais abordagens e modelos dedicados à relação entre expansão escolar e estratificação educacional em vários países. A análise comparativa permite que as questões discutidas em cada país tragam insights para discussão e melhor compreensão do caso brasileiro. Em seguida, usando dados das PNADs 2001, 2004 e 2007, serão testadas hipóteses relativas aos efeitos das origens sociais sobre as possibilidades de alcance educacional dos estudantes nos ensinos de segundo e terceiro graus no país, levando-se em conta as principais abordagens teóricas e analíticas internacionais, com especial atenção à hipótese da desigualdade efetivamente mantida. Esta análise pretende oferecer um quadro analítico da estratificação educacional no Brasil na primeira década do século XXI, tendo como pano de fundo a transmissão de desigualdades no acesso aos sistemas público e privado de educação, do ensino médio à universidade.

\section{EXPANSÃO EDUCACIONAL NO BRASIL}

A partir dos anos 1970 aprofundam-se as mudanças sociais, políticas e demográficas que criaram as condições sociais mais favoráveis para a população em idade escolar básica. A diminuição do número de filhos por mulher, o aumento da densidade populacional nas cidades e mais disponibilidade de escolas permitiram que as coortes mais jovens desfrutassem de um ambiente mais propício para a melhoria da realização escolar (Silva e Hasenbalg, 2000).

Nesse período, o número geral de matrículas do sistema de ensino foi multiplicado por 2,7 vezes. A taxa de analfabetismo cai de $50,5 \%$, em 1950, para 14,7\% em 1996 (Castro, 1998), e chega-se ao patamar de cerca de seis anos de educação média no país. O ensino fundamental duplicou de tamanho, a taxa líquida de escolarização da população de 7 a 
14 anos subiu para $96 \%$ no ano 2000, praticamente atingindo a universalização do acesso a este nível do sistema.

A expansão mais recente tem priorizado o ensino médio e o superior, o que, segundo Silva (2003), se deve a uma conjunção de aumento da demanda, políticas públicas, diminuição dos custos familiares e maior acessibilidade. $\mathrm{O}$ ensino médio passou de um patamar de um milhão para mais de sete milhões de estudantes matriculados. As maiores taxas de incremento neste nível são encontradas na região Nordeste, que, somente no período entre 1997 e 2002, apresentou elevação de $92 \%$ no número de matrículas - uma vez que concentrava maior contingente populacional até então fora do sistema escolar.

Estimativas indicam que após o ensino primário praticamente ter atingido cobertura universal, o ensino médio caminha na mesma direção, com cobertura de mais de $85 \%$ da população de jovens entre 15 e 17 anos de idade em 2001 (Soares e Alves, 2003). Contudo, a defasagem entre idade e série neste nível de ensino é muito alta, chegando a $51 \%$ em 2002, ou seja, mais da metade dos alunos que cursam o ensino médio foram reprovados pelo menos uma vez ao longo do ciclo escolar. Como essa proporção era de 76\% em 1970 (Silva, 2003), verifica-se progressiva redução da defasagem - possivelmente pela implementação de programas de ciclos e promoção automática, entre outros. No que toca à divisão setorial, a rede privada abrangia, em 1997, 27\% do total de matrículas do ensino médio, percentual que, dois anos depois, se reduz para 19\% (Cury, 2002).

Diferenças raciais e de gênero são marcantes nessa fase do sistema escolar. Dados da PNAD 2007 apontam que mulheres apresentam maior tendência a completar o ensino médio, seja em escola pública - 56\%, contra $44 \%$ de homens - ou privada - $52 \%$, contra $48 \%$-, e a entrar para a universidade $-61 \%$, contra $39 \%$ na rede pública, $55 \%$ contra $45 \%$ na rede privada. Já sobre diferenças entre grupos raciais, permanecem as desvantagens da população negra e parda no acesso e realização escolar no Brasil. Hasenbalg e Silva (1990) mostram que, além da maior proporção de crianças não brancas entre as que entram tardiamente na escola, entre as que não têm acesso algum ao sistema escolar a população não branca é três vezes maior que a branca. Além disso, apresentam uma trajetória escolar mais lenta e acidentada, com desvantagens em todos os níveis de ensino, mesmo nos níveis de maior renda familiar. Dados da PNAD 2007 mostram que enquanto não brancos são 
maioria a completar o ensino médio na escola pública - 54\%, contra $46 \%$ de brancos -, tornam-se minoria dos que concluem este nível na escola privada $-36 \%$, contra $64 \%$ de brancos. Na entrada para o nível superior, brancos são maioria nas duas redes - $61 \%$ na pública e $74 \%$ na privada.

O nível superior também se expandiu significativamente. Segundo Schwartzman (1988), desde os anos 70, em virtude da crescente demanda, houve um aumento considerável de instituições privadas, abrangendo um número de alunos que em poucos anos ultrapassou o de estudantes das universidades públicas. Criou-se um sistema de ensino superior altamente estratificado em universidades públicas de pesquisa concentrados na região Sudeste, universidades públicas espalhadas pelo país com nível de qualidade menor, e instituições privadas em vários estados do país com qualidade ainda menor.

De acordo com Martins (2000), este nível de ensino vem crescendo a uma média de $7 \%$ ao ano, considerando-se todas as modalidades e instituições, públicas ou privadas. O número de instituições de ensino superior atinge 973 em 1998, sendo que 79\% delas são privadas, e abrangem $62 \%$ das matrículas. Em 2004, de acordo com dados do INEP (2006), o número de matrículas no setor privado já chega a 71\%, ou seja, mais de dois terços do sistema superior de ensino, sendo que em 2006 o número de instituições neste setor atinge a incrível marca de $89 \%$.

Todavia, mesmo diante da visível expansão, o baixo rendimento interno do sistema escolar como um todo não consegue assegurar o acesso da maior parte da população que sai do nível primário aos níveis superiores, mostrando-se, assim, um sistema marcado por alto grau de seletividade. Após a quase universalização da educação primária, parte da pressão social desloca-se para a transição para o ensino superior. A cada mil alunos que iniciam seu ciclo escolar na primeira série do ensino primário, apenas $56(5,6 \%)$ tendiam a ingressar no ensino superior na década de 1970 (MEC, 2002). Em 2007, como mostram os dados da PNAD, essa quantidade sobe para $146(14,6 \%)$.

De acordo com relatório do INEP (2006), no que concerne à desigualdade de acesso, $50 \%$ dos jovens de 18 a 24 anos, provenientes de famílias com renda acima de cinco salários mínimos, estão matriculados em cursos de nível superior, enquanto apenas $12 \%$ dos jovens na mesma faixa de idade em famílias com até três salários mínimos estão matriculados neste nível. Como aponta Castro (2006), 70\% dos estudantes des- 
te nível de ensino vêm da camada dos $20 \%$ mais ricos do país. Políticas públicas implementadas na última década - como o REUNI e os programas de cotas e bônus das universidades públicas - têm ampliado as possibilidades de acesso de estudantes de camadas mais pobres ao ensino superior, mas o nível de acesso que proporcionam está longe de resolver o problema crônico de estratificação educacional.

O quadro geral, neste início de século, é de, por um lado, melhoria dos indicadores básicos, devido à melhoria social da família, mudanças estruturais (urbanização, industrialização, mudanças no mercado de trabalho) e melhor desempenho do sistema escolar como um todo (Silva e Hasenbalg, 2000; Silva, 2003). Por outro lado, não há indícios de redução da estratificação educacional, ou seja, do efeito das origens sociais sobre o alcance educacional dos indivíduos.

Boudon (1974) já havia advertido sobre a controversa relação entre expansão escolar e estratificação educacional, apontando que a primeira não leva necessariamente ao arrefecimento da segunda.

\section{PRINCIPAIS ABORDAGENS TEÓRICAS}

\section{A Hipótese Meritocrática}

A hipótese meritocrática postula que os processos de modernização social - maior desenvolvimento econômico e institucional, maior urbanização das sociedades e transição demográfica - são fatores que levam à diminuição do efeito das origens sociais sobre o alcance educacional do indivíduo (Treiman, 1970; Hauser e Featherman, 1976). O processo de desenvolvimento econômico ampliaria as oportunidades de educação para toda a sociedade, implicando a superação das limitações impostas pelas características adscritas, e a valorização das características adquiridas pelo indivíduo, principalmente relacionados a educação, ocupação, poder e prestígio (Davis e Moore, 1945; Lenski, 1966; Parsons, 1970; Treiman, 1970). A educação seria o principal vetor de mobilidade social, permitindo que indivíduos, independentemente de sua origem socioeconômica, raça ou sexo, alcançassem melhores posições do que sua geração anterior. Ou seja, indivíduos com origem em estratos diferentes da sociedade, homens ou mulheres, pretos ou brancos, teriam chances semelhantes de ter acesso à educação e, consequentemente, de alcançar boas posições no mercado de trabalho. Quanto mais moderna e industrializada uma sociedade, mais oportunidades educacionais ela oferece, mais extensivo é o alcance do siste- 
ma e maiores as chances de um indivíduo ascender socialmente através das habilidades conquistadas por seu alcance educacional, e não mais por critérios de origens familiares e herança de status social (Treiman, 1970). Nesse sentido, o desenvolvimento econômico, ao promover a universalização da educação, levaria a um processo de desestratificação da sociedade, equalizando as oportunidades de mobilidade social e aquisição de status.

Os efeitos deste processo são sintetizados por Treiman (1970) em proposições básicas, que pressupõem que: (1) a influência direta do status ocupacional do pai sobre o do filho deve ser mais fraca em sociedades mais industrializadas; (2) a influência direta da educação sobre o alcance ocupacional deve ser mais forte em sociedades mais industrializadas; (3) em sociedades mais industrializadas o status dos pais tem papel menos importante na realização educacional ${ }^{1}$.

Embora evidências tenham apontado para uma diminuição da desigualdade educacional ao longo do século (Hauser e Featherman, 1978), a aplicação empírica da teoria da modernização e da hipótese meritocrática tem mostrado resultados contraditórios, que serão discutidos a seguir.

\section{As Teorias Reprodutivistas}

Teóricos da reprodução social propõem enxergarmos o processo de expansão educacional não como mecanismo de universalização de oportunidades, mas, sim, como um mecanismo de reprodução das relações de dominação entre classes sociais (Bowles e Gintis, 1976; Bourdieu e Passeron, 1977; Collins, 1979).

Para os autores da teoria da correspondência (Bowles e Gintis, 1976), a escola deve ser entendida como uma instituição que, ao facilitar a integração de jovens ao mercado de trabalho, serve como mecanismo de perpetuação das relações sociais da vida econômica. O processo de escolarização funciona, assim, como mecanismo de internalização de valores, normas e comportamentos ditados pela classe dominante.

A teoria da violência simbólica (Bourdieu e Passeron, 1977), por sua vez, analisa as escolas como um campo social relativamente autônomo, em que a produção cultural torna-se instância de mediação de componentes que facilitam a reprodução social. Esta teoria afirma que o sistema educacional assegura a posição de grupos dominantes, enfatizando a 
comunicação desigual e o processo de socialização através do desconhecimento da natureza arbitrária das normas, resultando num tipo de instituição que mais conserva relações de desigualdades do que propicia inovações. O sistema privilegia aqueles estudantes equipados com mais capital cultural - bens e investimentos, materiais ou não, transmitidos, principalmente, pela família - e elimina progressivamente aqueles que não possuem o mesmo capital. Este mesmo sistema, através, sobretudo, da pedagogia escolar - todas as formas de instrução, sejam elas dentro da família, da escola, ou qualquer outro lugar -, ajuda a naturalizar as desigualdades no alcance escolar entre indivíduos oriundos de diferentes classes sociais, baseando-se em diferenças de mérito individuais, demonstradas através de procedimentos de teste. Falha durante a progressão das séries é atribuída à inadequação do indivíduo e por ele aceita como destino inexorável, passiva ou superficialmente contestada através do envolvimento em subculturas contraescolares. A violência simbólica reside, então, no sucesso da ação pedagógica que torna relações arbitrárias de poder em autoridade legítima.

Desigualdades oriundas do capital cultural são, assim, a primeira razão para a persistência da desigualdade social, de forma que a imposição de significados implica a reprodução da estrutura de distribuição de capital cultural e, consequentemente, da estrutura social em geral.

\section{A Abordagem da Escolha Racional}

Boudon (1974) e, posteriormente, Goldthorpe (1996), levantam críticas às teses funcionalistas, afirmando que só é possível entender a persistência das desigualdades no alcance educacional se se levar em conta dois tipos de efeitos: os primários, que criam diferenciais de classe no alcance inicial e, então, na "habilidade demonstrada" na escola; e os secundários, que operam por meio das decisões feitas pelos estudantes e seus pais sobre as opções presentes quando atingem determinando ponto de transição no ciclo escolar: ficar na escola ou não? Ter cursos acadêmicos ou vocacionais? Buscar um curso superior? Assim, o estudante e sua família têm sempre uma possibilidade de escolha, a qual é tomada com base nos custos e benefícios de cada opção. Se a avaliação de que a opção de prosseguir até os níveis mais altos não é tão favorável assim para a melhoria do nível de vida, estudantes oriundos das classes mais baixas optarão por encerrar os estudos mais cedo em busca de mais experiência no mercado de trabalho. No final, a estratificação do alcance educacional e do ocupacional resulta da avaliação que 
as famílias de classes sociais mais baixas fazem a respeito das opções mais ambiciosas como sendo menos favoráveis, reforçando os padrões de desigualdade no acesso às posições mais altas do sistema escolar e da estrutura de ocupações em geral.

Gerber (2000) acredita que o caso da Rússia enquadra-se nesta abordagem. O balanço entre custo e beneficio feito pelas famílias, tendo como pano de fundo crises econômicas e institucionais, não propicia uma percepção de redução dos custos do processo educacional, mesmo com processos de expansão e reformas. O balanço favorece, outrossim, um menor alcance ocupacional como forma de entrar mais rapidamente no mercado de trabalho, favorecendo a expansão de um setor informal cada vez maior no país.

\section{MODELOS ANALÍTICOS}

\section{O Modelo de Mobilidade Educacional}

Em trabalho pioneiro, Spady (1967) analisou a mobilidade educacional em termos de probabilidades de se completar transições educacionais nos EUA. Propôs-se a ver o sistema educacional como um processo de seleção que separa e elimina estudantes desprovidos de motivações, oportunidades e habilidades adequadas, em vários pontos do ciclo escolar, nos quais atritos em larga escala afetam as crianças das classes mais baixas nas primeiras transições do sistema. Calculando as probabilidades gamma para cada transição encontrou que, embora os níveis de alcance educacional tenham aumentado para todos os grupos de status ao longo das coortes, as diferenças entre estudantes de alta e baixa origem social no que diz respeito ao acesso à educação superior aumentaram. Por outro lado, o efeito da educação paterna sobre as chances de o filho iniciar e completar o ensino secundário decresceram ao longo das coortes. Quando a variável raça é introduzida, o alcance de brancos supera o de não brancos em todos os grupos de status e, embora estas diferenças sejam maiores nos níveis mais baixos de escolaridade, elas são consideráveis também nos níveis mais altos. Assim, ainda que tenha aumentado a ênfase no treinamento e na educação, que têm como consequência o enfraquecimento das características atribuídas por meio do status familiar, este mesmo treinamento pode aumentar a influência da origem social na diferenciação de status, uma vez que crianças oriundas de famílias com status mais alto apresentam vantagens competitivas especiais, derivadas de seu processo de socia- 
lização. Tais capacidades permitem que essas crianças tenham chances muito maiores de manter, ou mesmo melhorar, o nível de status em relação ao de seus pais, em comparação com crianças provenientes de famílias com status social mais baixo.

\section{O Modelo de Seletividade Diferencial}

O modelo de seletividade diferencial proposto por Mare $(1980,1981)$ se vale de regressões logísticas sobre as chances de um estudante atingir determinadas transições no ciclo escolar, levando-se em conta a evolução do efeito das origens sociais ao longo das coortes. Ao contrário dos modelos de regressão lineares até então utilizados (Blau e Duncan, 1967; Hauser e Featherman, 1976) - que indicam a estabilidade do efeito das origens sociais ao longo dos anos de escolaridade completos -, este modelo separa os efeitos marginais das distribuições e apresenta razões de chance mais confiáveis.

Este modelo mostrou que, nos EUA, as origens sociais influem de maneira diferenciada em cada uma das transições, cuja direção geral é o enfraquecimento do efeito das origens ao longo das transições, ou seja, o efeito da origem social é mais forte nas primeiras transições, para o ensino básico e secundário. Isto se explica, na mesma direção proposta por Spady, pelo processo de seleção social que faz com que crianças de classes sociais mais baixas encarem barreiras seletivas severas nas primeiras transições educacionais, o que faz com que só os estudantes mais dedicados e motivados provenientes destas classes consigam progredir até as transições mais elevadas. Quando as taxas de transição são altas, somente os estudantes menos motivados e dedicados das classes baixas falharão, e quando as taxas forem baixas, somente os mais dedicados conseguirão progredir. Nesse sentido, a correlação entre origem socioeconômica e variáveis intervenientes - como atitudes e motivações, geralmente não medidas nas pesquisas - que determinam o sucesso educacional é menor quanto mais alta for a transição, fazendo com que, dessa forma, o efeito indireto da origem, mediado pela atitude e motivação, seja reduzido ao longo das transições.

Mare encontrou um padrão constante de efeito ao longo das coortes, ou seja, o efeito das origens sociais não é diferente entre indivíduos de coortes mais novas e mais velhas dentro de cada ponto de transição, batendo de frente com os postulados da teoria da modernização. 
A coletânea organizada por Shavit e Blossfeld (1993), propõe uma análise dos sistemas de estratificação educacionais em treze países, a partir do modelo de seletividade diferencial ${ }^{2}$. As evidências desta coletânea apontam que em praticamente todos se verifica a diminuição do efeito das origens sociais ao longo das transições e a estabilidade do efeito das origens sociais sobre o alcance escolar ao longo das coortes. Embora as proporções de estudantes de todas as classes sociais que atendem a todos os níveis educacionais tenham aumentado, as vantagens associadas com as origens sociais mais privilegiadas persistem em quase todos os países. As únicas exceções são a Suécia e a Holanda, onde houve declínio do efeito das origens sociais por conta de políticas de equalização de condições socioeconômicas. Os pesquisadores concluem sobre a aplicabilidade das propostas do modelo de seletividade diferencial e propõem um padrão universal de entendimento dos sistemas de estratificação educacional: os sistemas se abrem, passo a passo, da base para cima, de forma que as coortes vão sucessiva e lentamente avançando dentro da hierarquia educacional, mas os maiores níveis educacionais permanecem razoavelmente exclusivos, o que faz com que verdadeiros gargalos sejam criados na transição para o nível superior, privilegiando o acesso daqueles oriundos de grupos socioeconomicamente avantajados.

Treiman et alii (2003), analisando 29 países, a pontam que, embora em todos tenha havido uma enorme expansão educacional, os efeitos das origens sociais permaneceram estáveis em pelo menos vinte países, ao passo que nos outros verifica-se declínio do efeito da educação do pai, e em outros se verifica aumento.

Tais modelos foram também aplicados para o Brasil. Silva et alii (1985) analisaram tendências temporais na estratificação educacional brasileira e encontraram uma forte estabilidade temporal do efeito das origens sociais, principalmente da educação paterna, no alcance educacional dos filhos, ao longo de coortes entre 1912 e 1956. Os autores concluíram que a sociedade brasileira permaneceu com a mesma estrutura de estratificação educacional nesse período de 40 anos, apesar do reconhecido processo de desenvolvimento e modernização socioeconômica, contrariando as proposições da tese da modernização.

Silva (2003) analisa o processo de expansão educacional entre 1981 e 1999, valendo-se de dados das PNADs para estes dois anos, mais o ano de 1990. O estudo revelou que a transição para a primeira série do ensi- 
no básico atinge a quase universalização de acesso e que, em consonância com os achados dos estudos anteriores, o efeito das variáveis de origem social tende a declinar progressivamente ao longo das transições, exceto pelas variáveis renda - cujo efeito aumenta ao longo das transições, refletindo o impacto da ampliação do ensino privado pago - e raça, cujo efeito também cresce conforme se eleva a transição. Os resultados indicam o deslocamento da seletividade econômica e racial para os níveis mais elevados do ciclo escolar. No que concerne às tendências temporais, estas indicam certa estabilidade no efeito da renda e uma diminuição gradual do efeito da cor ao longo dos anos, indicando uma tendência à diminuição das desigualdades de cor na realização escolar ao longo das coortes.

Fernandes (2005) analisa dados da PNAD 1988, principalmente no que se refere ao efeito das origens socioeconômicas, da raça e origem urbana nas transições escolares. Encontra uma redução do efeito da educação dos pais ao longo das coortes, mesmo padrão apresentado pelo gênero. Contudo, o efeito de raça e origem urbana apresenta padrão oposto, pois indivíduos com origem urbana tendem a alcançar maior realização educacional, e raça apresenta um efeito significante e crescente ao longo das coortes. A autora conclui que o efeito da origem socioeconômica é forte nos primeiros níveis educacionais e fraco nos últimos, o que implica que os indivíduos que alcançam níveis educacionais superiores são mais homogêneos em relação à herança socioeconômica e dependem mais de habilidades e motivação para prosseguirem na sua realização educacional do que de suas origens socioeconômicas. O efeito da raça, por outro lado, indica que as barreiras dentro do sistema educacional são fortes e resistem à expansão. A pesquisadora conclui que as proposições do modelo de Mare só podem ser apoiadas parcialmente para o Brasil, pois, embora a maioria das variáveis de origem apresente efeito decrescente da primeira à última transição (12 anos ou mais de escolaridade), tal proposta, que diz que a diminuição dos efeitos de origem ao longo das transições se explica pela diminuição na heterogeneidade de origens sociais, não nos diz por que o efeito da raça é tão alto nas últimas transições.

Por fim, Torche (2010), analisando dados da Pesquisa de Padrões de Vida 1996/1997, mostra que houve um aumento das desigualdades de acesso às transições para se completar o ensino médio e entrar para a universidade ao longo das coortes no Brasil e em outros países da América Latina. Aponta que o processo de expansão educacional no 
Brasil pode ser comparado ao de outros países como a Rússia, onde o agigantamento da educação básica, e até mesmo do ensino médio, que propiciou mais alcance educacional a todas as classes, não é acompanhado pelo ensino superior, criando-se um verdadeiro gargalo nessa transição, aumentando, assim, a competição por um número escasso de posições privilegiadas.

\section{A Abordagem do Curso de Vida}

Em estudo sobre países europeus, Muller e Karle (1993) mostram que todos apresentam o mesmo padrão nas taxas de transição, sendo o efeito das origens sociais mais alto na primeira transição, para o ensino básico, tornando-se menor à medida que avançam as transições. A principal explicação para esse efeito, segundo estes pesquisadores, não reside na maior seleção social nas primeiras transições, mas recai sobre as mudanças nas relações entre estudantes e seus pais. Ao passar das transições, e à medida que os estudantes se tornam mais velhos, eles ficam menos dependentes dos pais socioeconomicamente, o que, portanto, define que o efeito das origens deve ser gradativamente menor ao longo das transições.

\section{A Hipótese MMI}

Tendo como referências o modelo analítico da seletividade diferencial e a abordagem da escolha racional, Raftery e Hout (1993) propuseram a hipótese da desigualdade maximamente mantida - maximally maintained inequality (MMI) - a partir da análise dos efeitos da expansão do sistema de ensino irlandês. Esta hipótese propõe que a desigualdade de acesso a um determinado nível de ensino só declinará quando houver saturação do acesso àquele nível por parte dos estudantes oriundos das classes sociais privilegiadas e, assim, a pressão desloca-se para as transições subsequentes do sistema escolar.

A hipótese postula que a expansão do sistema educacional não implica necessariamente a redução das desigualdades sociais, mas, sim, que estas tendem a permanecer estáveis, ou mesmo a se ampliarem, uma vez que os grupos já em vantagem aproveitarão melhor as novas posições disponibilizadas. As taxas de transição e razões de chance entre origens sociais e transições educacionais permanecem, então, as mesmas para sucessivas coortes, a não ser que elas sejam forçadas a mudar devido ao aumento das matrículas. Somente quando houver uma saturação nas chances de determinados grupos em vantagem completarem 
uma transição - algo próximo a 100\% de acesso - é que os níveis de desigualdade começam a cair. Segundo os propositores da tese, a MMI pode ser tomada como parâmetro para estudos comparados de estratificação educacional, pois consegue captar a dinâmica da expansão e diferenciação dos sistemas educacionais num número considerável de países.

A coletânea de Shavit e Blossfeld (1993) aponta que a MMI é plausível para vários dos países estudados, exceto para aqueles onde a queda das desigualdades ocorreu antes da saturação da educação básica pelos grupos privilegiados (Suécia e Holanda), ou a saturação do acesso à educação básica ocorreu sem que necessariamente as desigualdades tivessem sido reduzidas como consequência (Estados Unidos). Ambos os casos indicam que a MMI não consegue explicar um modelo universal de redução dos efeitos das origens sociais, no sentido de que ela não é capaz de prever todas as formas pelas quais a desigualdade no alcance escolar pode ser realizada.

Sobre sua validade para o caso da expansão escolar brasileira, Silva (2003) a ponta que a quase universalização do acesso à primeira transição, a redução dos efeitos das variáveis de origens sociais ao longo das transições, e o consequente deslocamento da seletividade escolar para os níveis mais altos poderiam ser tomados como indicativos da saturação no nível básico de ensino e deslocamento das desigualdades nas chances de escolarização para os níveis mais elevados. Por outro lado, o comportamento do efeito da variável raça, que aumenta nas transições mais altas, mas diminui ao longo das coortes, e as declinantes diferenças entre áreas rurais e urbanas, são destoantes e não permitem aceitar a MMI como totalmente aplicável neste contexto.

\section{A Hipótese EMI}

Estudos recentes mostram que o modelo logístico de transições, até então utilizado por boa parte dos trabalhos sobre estratificação educacional, apresenta uma limitação relacionada à suposição de que indivíduos progridem ao longo do sistema educacional numa sequência unilinear (Breen e Jonsson, 2000; Lucas, 2001). O modelo de seletividade diferencial e a MMI, cujos pressupostos se baseiam neste modelo, não seriam capazes de perceber os aspectos qualitativos do processo de estratificação educacional em tempos de expansão. Em muitos países o sistema educacional divide-se em caminhos alternativos (tracking) nos 
quais os indivíduos, diferenciados tanto por suas origens sociais quanto pelo empenho escolar, podem realizar diferentes probabilidades de continuação escolar.

Ao ignorar tais aspectos qualitativos, o modelo logit tradicionalmente usado tende a subestimar o efeito da origem social nas primeiras transições e superestimar este efeito na transição para a educação superior (Breen e Jonsson, 2000). Além disso, sofre com um problema de heterogeneidade não mensurada, que surge como possível explicação para o declínio dos efeitos das origens sociais ao longo das transições, o que é reconhecido por Mare (1994), que introduz informações sobre irmãos dos estudantes para tentar corrigir esse problema ${ }^{3}$.

Breen e Jonsson (2000) estimam, então, modelos logísticos multinomiais para estudo do processo de estratificação educacional na Suécia. Controlam pelo desempenho do estudante, em termos de notas, para minimizar efeitos de seleção devido à habilidade cognitiva. Mostram que o track escolhido pelo estudante influencia a probabilidade de realizar transições subsequentes, e que as probabilidades de se completar a transição para a educação superior é altamente correlacionada com o nível educacional dos pais, o que faz com que estudantes de classes em desvantagem, para completarem esta transição, tenham maior suporte da escola e de seu próprio desempenho.

Nesta linha de argumentação, Lucas (2001) propõe a hipótese da desigualdade efetivamente mantida (EMI), que afirma que atores com vantagens socioeconômicas asseguram para si mesmos e sua família algum grau de vantagem onde quer que seja possível, seja quantitativa ou qualitativa. Enquanto a MMI sugere que a competição por um nível de educação que já é universal será zero, a EMI propõe que mesmo em níveis universalizados existirá competição, a qual ocorrerá pelo tipo, ou qualidade, da educação alcançada. Uma vez que determinado nível educacional atinja saturação, em vez de a pressão ser necessariamente deslocada para o nível superior, como pressupõe a MMI, desigualdades nas chances de alcance educacional neste nível podem ser substituídas por desigualdades nas chances de acesso aos caminhos mais seletivos e prestigiados. Filhos de pais em vantagem socioeconômica serão alocados para posições vantajosas quantitativa e qualitativamente no sistema escolar.

Analisando dados para o sistema escolar dos EUA, onde a expansão do sistema de ensino foi feita à base da diferenciação de tracks, o acadêmi- 
co e o vocacional, no ensino secundário e superior, Lucas mostra a plausibilidade dessas proposições, indicando que estudantes provenientes de classes sociais mais altas, mesmo que muitas vezes apenas medianos em termos de habilidades, apresentam mais chances de serem alocados para o caminho com mais prestígio (track acadêmico) do que um estudante dedicado proveniente de classes mais baixas, o qual tem grandes chances de ser alocado para um community college, caminho com menor prestígio. Este último caminho é atrativo para crianças oriundas de famílias mais modestas, uma vez que fornece habilidades básicas que facilitam o acesso mais rápido ao mercado de trabalho, mesmo que apenas para ocupações de baixo status social. Os achados indicam ainda que a origem social (educação dos pais e renda familiar), além do número de irmãos, importam mais para a transição ao ensino superior que para se completar o ensino secundário, o que, segundo o autor, joga por terra um dos principais pressupostos da abordagem do curso de vida - de que o feito diminui ao longo das transições dada a menor dependência dos estudantes em relação a seus pais à medida que estes vão ficando mais velhos -, mas está de acordo com o pressuposto da MMI do deslocamento da seleção social para os níveis mais altos à medida que os mais baixos vão atingindo saturação. A expansão do ensino secundário e superior no país não implicou, assim, a redução de desigualdades e o fim da competição, como prevê a MMI, mas, sim, deixou mais claro que o ensino secundário é um importante espaço de competição, no qual a origem social importa muito.

Ayalon e Shavit (2004) estimaram modelos multinomiais para a realização escolar em Israel. Mostram que a elegibilidade para o track acadêmico está correlacionada com etnicidade e classe social, de forma favorável a judeus de origens étnicas europeias, membros das classes sociais mais altas. Encontraram que o efeito das origens sociais sobre o alcance educacional passa a declinar ao longo das coortes, mesmo antes da saturação. Contudo, os que mais se beneficiaram foram os grupos étnicos mais privilegiados, que asseguram mais chances de admissão por uma universidade de prestígio. A expansão mediante a diferenciação cria uma situação em que a educação se torna, sim, mais acessível, mas também vem acompanhada do fato de que os grupos mais fortes retêm hegemonia sobre o track acadêmico, cujo retorno no mercado de trabalho é maior do que o track vocacional. A disponibilidade de educação vocacional habilitou o sistema a absorver grupos em desvantagem no nível secundário sem perturbar os interesses sociais de grupos em vantagem na estratificação educacional. 
A expansão do ensino pós-secundário nos EUA também pode ser entendida sob essa mesma perspectiva. Achados de vários trabalhos indicam que o aumento das taxas de matrícula de minorias na educação superior foi maior que as de brancos, mas que, por outro lado, estas minorias étnicas estão sobrerrepresentadas em programas de dois anos e community colleges, enquanto o acesso às melhores universidades é maior entre brancos (Ayalon et alii, 2001; Karen, 2002).

Hout (2006) compara a estratificação educacional em 25 países participantes do International Social Survey Programme (ISSP) em 1999, entre eles o Brasil, a fim de verificar a pertinência das hipóteses MMI e EMI. Mostra que a MMI encontra suporte nas economias de mercado, mesmo naquelas em desenvolvimento, como o Brasil, uma vez que o efeito das variáveis de origem social incluídas nos modelos cai à medida que estes países atingem saturação nos níveis básicos de educação. Por outro lado, a MMI não se aplica a sociedades que fizeram parte do bloco socialista, pois entre estas o efeito da origem social sobre o alcance educacional diminui com as coortes sem que tenha havido saturação dos níveis básicos quando o efeito começou a diminuir e, assim, o resultado não é consistente com a MMI, mas plausível para a EMI. Para o autor, isso é explicado pela capacidade de os governos socialistas, antes de 1991, diminuírem desigualdades entre classes sociais.

\section{A Hipótese da Transformação Socialista}

Pesquisas em países participantes socialistas, todavia, apontam o outro lado dessa questão. Szelenyi e Aschaffenberg (1993), para a Hungria, Wong (1998), para a Tchecoslováquia, Heyns e Bialeck (1993), para a Polônia, Zhou et alii (1998), para a China, e Gerber (2000), para a Rússia, indicam a persistência, ou mesmo o recrudescimento, das desigualdades sociais, embora seja fato que oportunidades educacionais para as classes mais baixas foram expandidas com o estabelecimento do regime socialista. A hipótese da transformação socialista argumenta que o efeito das origens sociais reemerge posteriormente a um período de declínio e relativa equalização das oportunidades educacionais, dado que o socialismo gera uma nova classe de burocratas similar às classes dominantes em economias capitalistas, e que usa políticas de Estado para obter privilégios para eles mesmos e suas famílias. As novas elites estabelecem seus privilégios e ganham controle sobre o sistema escolar, assegurando vantagens para seus próprios filhos. 
Como aponta Gerber (2000), a Rússia apresenta uma das histórias de maior sucesso entre países do bloco comunista. Em 1989, 94\% da população urbana e $84 \%$ da população rural haviam completado pelo menos o nível secundário. Criou-se, aí, um gargalo, dado que o ensino superior não se expandiu na mesma proporção que os anteriores, e, assim, a pressão por acesso foi deslocada para este nível. As ações não foram capazes de promover a equalização geral das oportunidades, persistindo o efeito das origens sociais e mesmo do lugar de residência (Gerber e Hout, 1995). Crises econômicas e caos político desde o esfacelamento do regime socialista tiveram forte impacto negativo no sistema educacional, cuja proporção da retração não encontra similar no início dos anos 90. Como consequência, houve um aumento ainda mais significativo da magnitude das desigualdades de acesso ao nível superior. As evidências do efeito das origens sociais derivadas da formação de uma classe burocrática são ainda mais destacadas. Gerber (2000) mostra que, além das variáveis clássicas de origem socioeconômica, o fato de um dos pais ter pertencido ao Partido Comunista exerce uma enorme influência sobre as oportunidades educacionais dos filhos em coortes mais jovens, aumentando o alcance escolar. De acordo com Treiman et alii (2003), a reprodução educacional apresenta-se atualmente muito forte entre nações antes pertencentes ao bloco comunista, maior até do que em várias economias de mercado.

\section{HIPÓTESES}

São três as principais hipóteses a serem testadas nas análises:

Hipótese 1: Baseando-se na literatura sobre os modelos de transição, testa-se que o efeito das origens sociais não diminui ao longo das coortes - no caso deste trabalho, ao longo da década -, ao contrário do que proporia a teoria da modernização;

Hipótese 2: Baseando-se na hipótese da desigualdade maximamente mantida, será testada a suposição de que o efeito das origens sociais é maior na transição para o ensino superior que na transição para a conclusão do ensino médio;

Hipótese 3: Tendo como referência a hipótese da desigualdade efetivamente mantida, testa-se que grupos sociais com vantagens socioeconômicas e de capital cultural procuram resguardar para seus filhos o tipo de ensino mais prestigiado e que traduz mais vantagens futuras. 


\section{METODOLOGIA DE ANÁLISE}

\section{Fontes de Dados}

Os dados são provenientes da Pesquisa Nacional por Amostra de Domicílios (PNAD), realizada pelo IBGE. A pesquisa entrevista indivíduos em todo o país, baseando-se numa amostra de domicílios estratificada por clusters.

O estudo baseia-se em dados das PNADs 2001, 2004 e 2007. A PNAD 2007 é a última rodada da pesquisa que está disponível para o público acadêmico, e somente a partir de 2001 a PNAD passou a incluir uma questão sobre a rede de ensino cursada pelo indivíduo, se pública ou privada.

São utilizadas subamostras para cada ano da pesquisa. O primeiro seleciona apenas indivíduos cuja condição na família é filho(a), a fim de se poder estimar o efeito da origem social (pais) sobre o alcance educacional. O segundo corte refere-se à idade, quando são escolhidos aqueles que estejam entre 17 e 25 anos, dado que 17 é a idade regular para se completar o ensino médio, e 25 é a idade na qual a maioria dos indivíduos já completou o seu ciclo escolar. As subamostras resultantes são de 26.555 indivíduos para 2001 - 15.570 para a transição 1, e 10.985 para a transição 2 -,34.404 para 2004 - 19.075 na transição 1, e 15.329 na transição 2 - e 36.293 para 2007 - 19.344 na transição 1, e 16.949 na transição 2.

A interpretação dos coeficientes dos modelos seguirá estratégia sugerida para amostras estratificadas (Hasenbalg e Silva, 1991; Silva, 2003; Fernandes, 2005). Sugere-se que conclusões feitas a partir deste método de amostragem não sejam interpretadas da mesma forma que as obtidas a partir de amostras aleatórias simples, uma vez que estimações feitas a partir de amostras estratificadas e multiestágio tendem a subestimar o erro padrão. Assim, o t de student maior que 3 é a opção sugerida para se evitar a subestimação do erro.

\section{Variáveis}

As variáveis independentes incluídas nos modelos foram inspiradas no trabalho de Silva (2003), que introduz um modelo com variáveis relacionadas tanto ao indivíduo quanto ao domicílio e ao contexto regio- 
nal. Foram acrescentados termos interativos . Todas as variáveis são descritas a seguir.

\section{Variáveis Dependentes}

As variáveis dependentes referem-se às transições escolares:

Transição 1 (t1): dado que iniciou o ensino médio, se o completou ou não; a variável é codificada em 0 para os que abandonaram este ciclo antes de terminá-lo (referência), em 1 para os que o completaram em escola pública, e em 2 para os que o completaram em escola privada.

Transição 2 (t2): dado que completou o ensino médio, se iniciou educação superior ou não; codificada em 0 para os que concluíram o ensino médio, mas não buscaram vaga na educação superior (referência), 1 para os que buscaram vaga em universidades públicas e 2 para os que buscaram vaga em universidade privada.

T2 (referência: escola pública): esta variável é uma recodificação da anterior, na qual a referência é agora a escola pública. Permitirá mensurar a diferença direta entre completar uma transição na escola privada, em relação à escola pública.

\section{Variáveis Independentes}

Idade: variável de controle do fluxo do indivíduo no sistema escolar. Neste estudo, sua amplitude é dos 17 aos 25 anos. Idade ao quadrado é introduzida para captar a medida na qual a idade passa a exercer efeito negativo sobre a escolaridade.

Gênero: tendo em vista o maior alcance educacional feminino, esta variável dicotômica apresenta homens com valor 0 e mulheres com valor 1 .

Raça: codificada em duas variáveis indicadoras, uma para pardos ( pardos $=1$ e outros $=0$ ) e outra para brancos (brancos $=1$ e outros $=0)$, tendo como referência a categoria pretos. Embora seja comum agregar pardos e pretos como não brancos - ver, por exemplo, Silva e Hasenbalg (2000) e Silva (2003) -, será analisado em que medida estas categorias sociais apresentam chances diferentes de sucesso nas transições educacionais, sendo, por isso, separadas aqui ${ }^{4}$. 
Educação do chefe: variável que representa o capital cultural da família, codificada em anos completos de escolaridade do indivíduo caracterizado como chefe da família. Mensura o impacto deste capital nas possibilidades de um indivíduo completar determinada transição.

Renda familiar per capita: mede o impacto do capital econômico familiar sobre as probabilidades de o estudante alcançar alguma das transições. Espera-se que quanto maior a renda, maior o acesso à educação superior, e, em especial, às universidades da rede privada; a amplitude da renda familiar é de 0 até 30 salários mínimos, no intuito de se evitar que outliers atrapalhem a análise.

Chefia feminina: assim como utilizada em Lucas (2001) e Silva (2003), é indicadora de "família quebrada"; espera-se que em familias com chefia feminina estudantes apresentem menor probabilidade de completar as transições, em relação a abandonar a escola.

Número de filhos: indica o peso da composição familiar sobre as possibilidades de alcance educacional, de forma que em famílias com maior número de filhos a probabilidade de estes completarem as transições são menores. Também funciona como controle da heterogeneidade não mensurada.

Área: dadas as maiores dificuldades de acesso aos ensinos médio e superior em áreas rurais, esta variavel foi codificada em duas variáveis indicadoras: uma para áreas metropolitanas e outra para áreas urbanas não metropolitanas, tendo áreas rurais como referência.

Região: o Nordeste, por seu menor nível educacional geral, foi definido como categoria de referência para três variáveis indicadoras: Sudeste, Sul e Norte/Centro-Oeste.

Termos interativos foram estimados entre a renda familiar ou educação do chefe e raça, chefia feminina e regiões do país.

\section{Modelos de Análise}

Tendo como referência o modelo proposto pela hipótese EMI, as análises deste trabalho serão baseadas em modelos logísticos multinomiais.

Serão estimados três modelos para cada ano da PNAD: um para a transição 1 e outro para a transição 2 , nos quais os indivíduos que abandonam a escola são categoria de referência, e o último também para a 
transição 2, mas com a escola pública como referência. Temos então um total de nove modelos.

\section{Limitações do Modelo}

Levando-se em conta que a PNAD não é um survey especializado em estratificação educacional, variáveis importantes para um estudo completo das transições educacionais não estão presentes no banco de dados. Os modelos aqui estimados não permitirão, como o de Lucas (2001), mensurar como o desempenho e o caminho do estudante até determinada transição influenciam na sua alocação naquela transição.

O problema de heterogeneidade não mensurada é reduzido dada a presença da variável relativa ao número de filhos no domicílio, em estratégia similar à apresentada por Mare (1994) e Lucas (2001).

\section{Estatísticas Descritivas}

A Tabela 1 indica a proporção de indivíduos em cada tipo de transição e rede escolar, para os três anos da pesquisa analisados.

Tabela 1

Proporção de Estudantes, por Rede de Ensino e Transição Escolar Brasil, 2001, 2004, e 2007

\begin{tabular}{c|l|cc|cc|cc}
\hline \multirow{2}{*}{ Transições } & \multirow{2}{*}{ Caminhos } & \multicolumn{2}{|c|}{$\mathbf{2 0 0 1}$} & \multicolumn{2}{|c|}{2004} & \multicolumn{2}{c}{2007} \\
\cline { 3 - 8 } & & $\mathbf{N}$ & $\mathbf{\%}$ & $\mathbf{N}$ & $\mathbf{\%}$ & $\mathbf{N}$ & $\mathbf{\%}$ \\
\hline \multirow{3}{*}{$\begin{array}{c}\text { Transição 1 (completar } \\
\text { ensino médio) }\end{array}$} & Não completou & 7.137 & 45,8 & 8.040 & 42,1 & 7.680 & 39,7 \\
\cline { 2 - 8 } & Rede pública & 7.452 & 47,9 & 7.679 & 40,3 & 8.715 & 45,1 \\
\cline { 2 - 8 } & Rede privada & 981 & 6,3 & 3.356 & 17,6 & 2.949 & 15,2 \\
\hline \multirow{3}{*}{$\begin{array}{c}\text { Transição 2 (acesso à } \\
\text { educação superior) }\end{array}$} & Não completou & 8.434 & 76,8 & 11.037 & 72 & 11.667 & 68,8 \\
\cline { 2 - 8 } & Rede pública & 745 & 6,8 & 1.269 & 8,3 & 1.684 & 9,9 \\
\cline { 2 - 8 } & Rede privada & 1.806 & 16,4 & 3.023 & 19,7 & 3.598 & 21,2 \\
\hline
\end{tabular}

Fonte: Elaboração própria a partir de dados das PNADs 2001, 2004 e 2007.

Tendências apresentadas na Tabela 1 indicam a diminuição gradual do número de estudantes que abandonam a escola sem completar o ensino secundário, a constância dos que completam esta transição no sistema público e aumento do número de estudantes que completam o ensino médio no sistema privado. A rede pública representa a maioria dos que completam esta transição. 


\section{Arnaldo Mont'Alvão}

Para a transição 2 também se verifica a diminuição gradual do número de indivíduos que abandonam a escola antes de entrar para a universidade e, consequentemente, o aumento dos que completam esta transição, tanto na rede privada quanto na pública. A rede privada abrange a maioria dos que completam esta transição, evidenciando a superioridade quantitativa da rede privada nesta transição escolar.

As correlações entre as variáveis envolvidas nos modelos indicam que não há problemas de colinearidade entre elas que afete a confiabilidade dos modelos ${ }^{5}$.

\section{Resultados}

As tabelas a seguir apresentam os resultados dos modelos estimados.

Destaca-se, em primeiro lugar, o ajuste dos modelos. O qui-quadrado $\left(\chi^{2}\right)$ é o mecanismo utilizado. Os modelos apresentam 28 graus de liberdade. Assim, comparando-se o qui-quadrado dos modelos com o qui-quadrado de referência a 28 graus de liberdade $(41,337)$, todos os modelos estimados apresentam qui-quadrados muito superiores ao de referência, mostrando-se assim bem ajustados.

O pseudo $R^{2}$ (Cox e Snell) indica que as variáveis incluídas explicam de $24 \%$ a $27 \%$, em 2001, $29 \%$ a $41 \%$, em 2004, e $26 \%$ a 37\%, em 2007, da variância ${ }^{6}$. Comparando-se com o $R^{2}$ de $27 \%$ encontrado por Ayalon e Shavit (2004) para o caso israelense, verifica-se que os modelos explicam proporção semelhante a modelos para outros contextos.

Nas tabelas seguintes, os coeficientes indicam a razão de chance $\left(\operatorname{Exp}^{\beta}\right)$ de um indivíduo, com determinada característica, completar a transição na rede pública, ou privada, em relação aos que abandonaram a escola sem completar a transição ${ }^{7}$. A probabilidade final é dada por: $\left(\operatorname{Exp}^{\beta}-1\right) * 100$. A coluna 5 diz respeito ao modelo que tem como referência a escola pública. A coluna que indica a relação entre abandonar a escola e a escola pública neste modelo foi suprimida, já que ela também repetiria a coluna 3 .

Os coeficientes com significância estatística $(t>3)$ são indicados por um asterisco. Os termos interativos, estimados separadamente, foram incluídos nestas tabelas para aproveitamento de espaço. 
Estratificação Educacional no Brasil do Século XXI

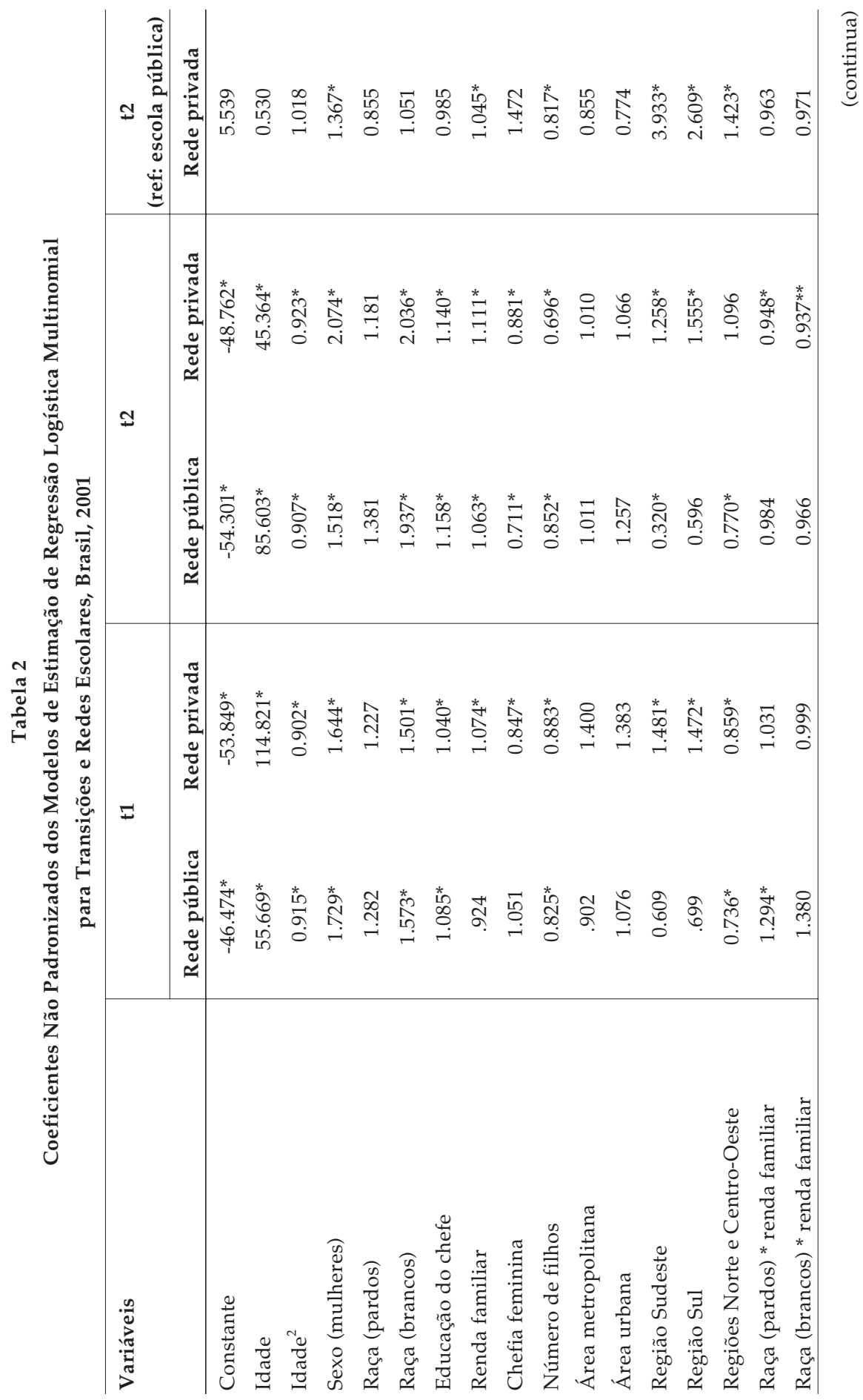




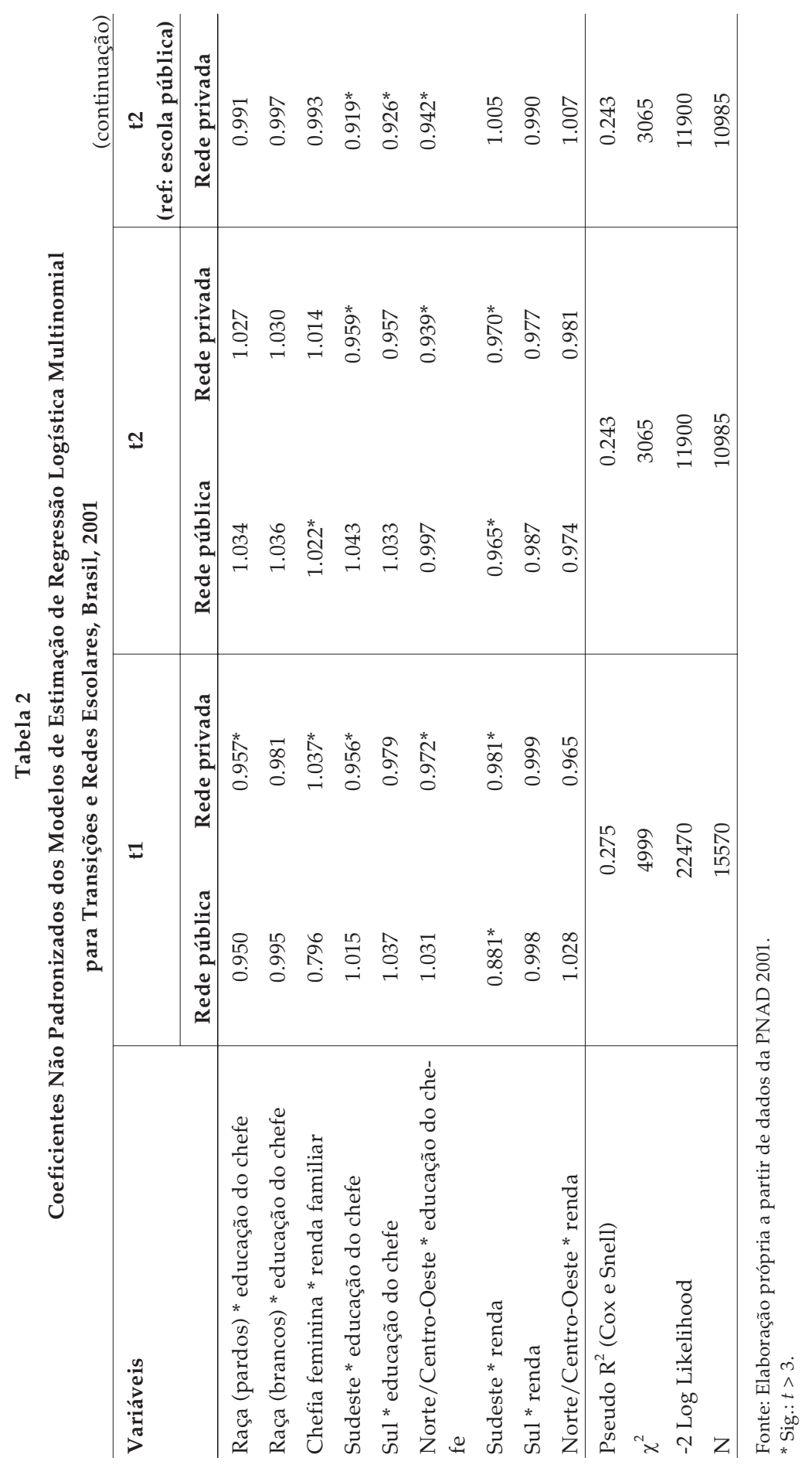


Estratificação Educacional no Brasil do Século XXI

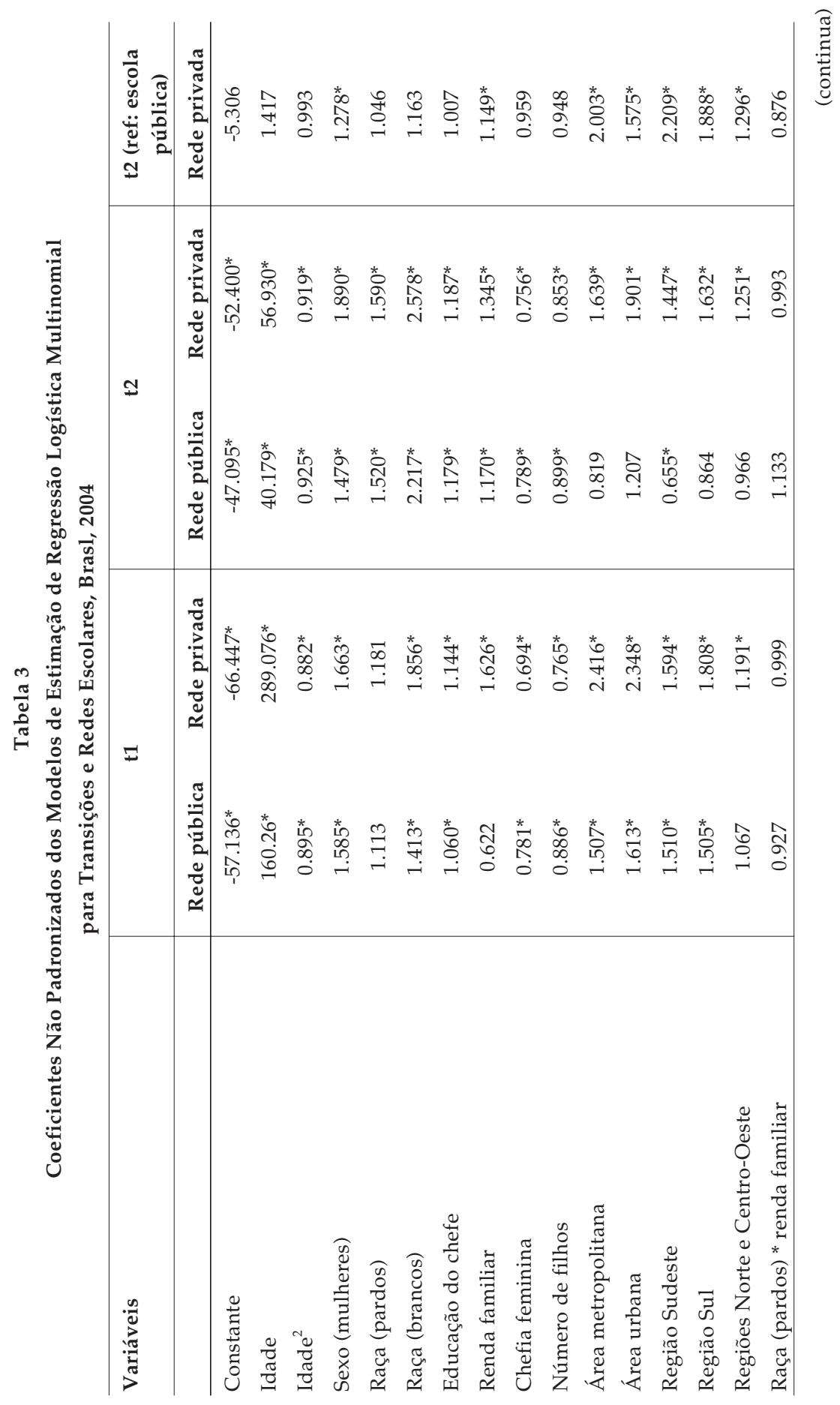




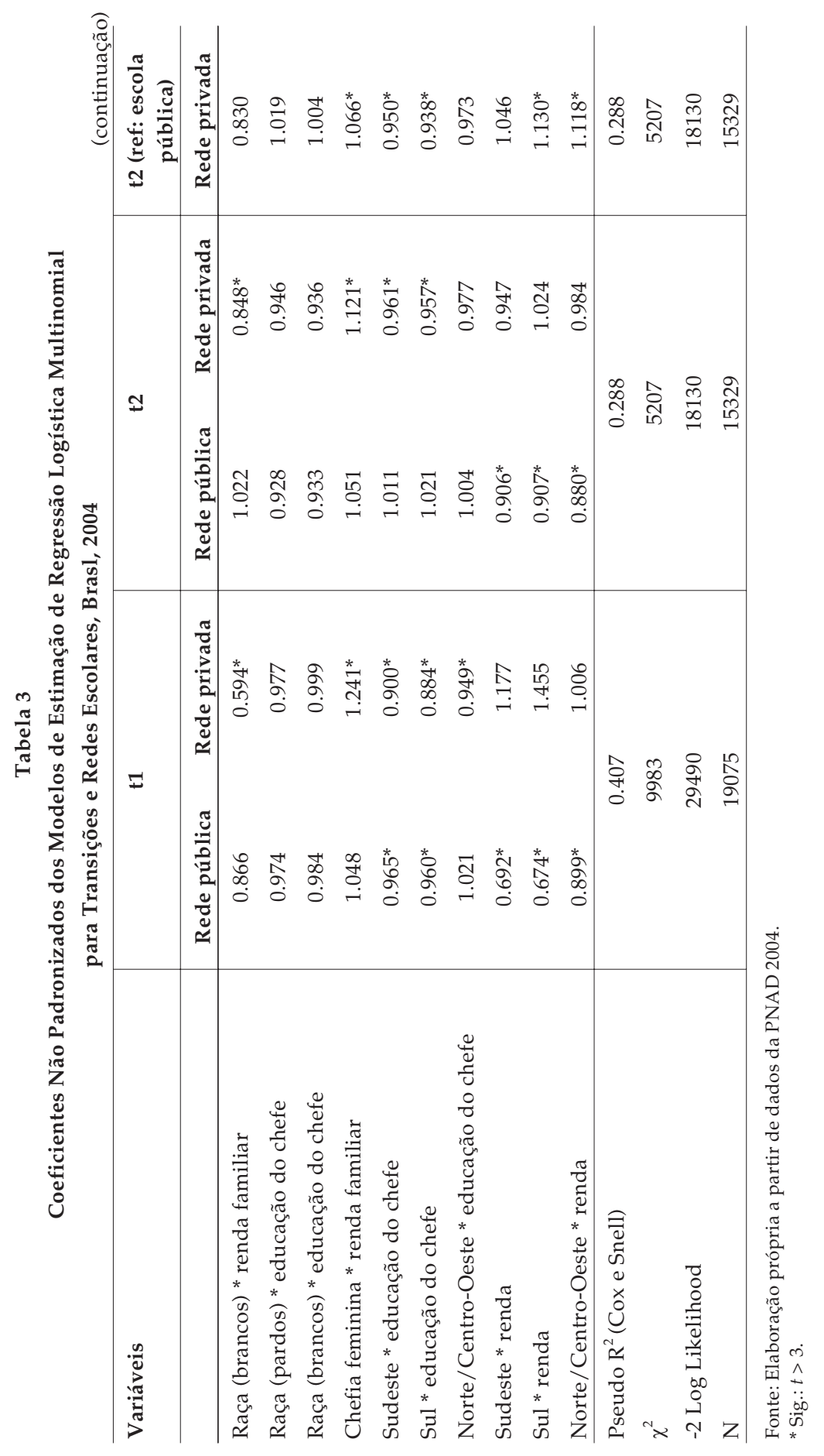


Estratificação Educacional no Brasil do Século XXI

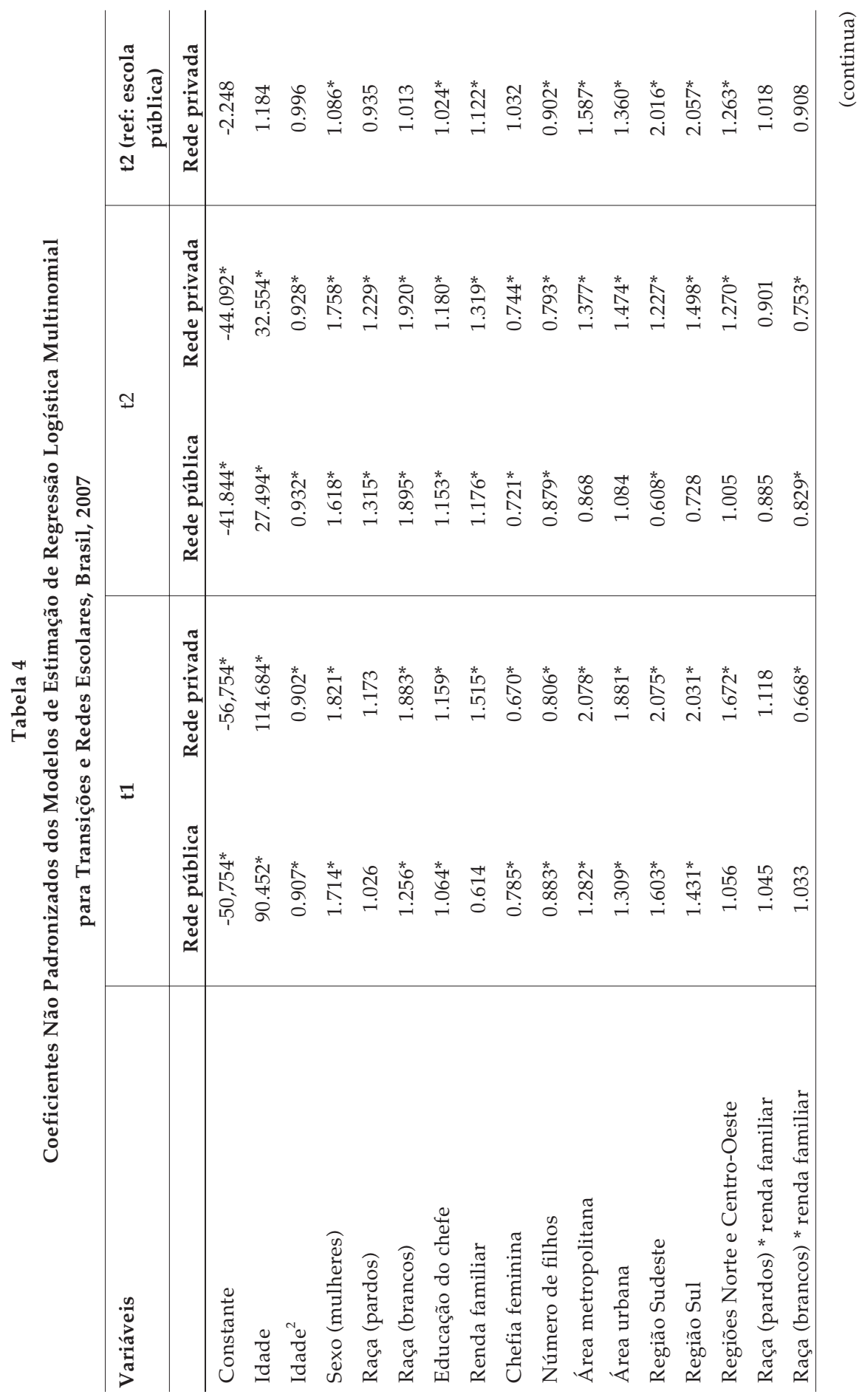




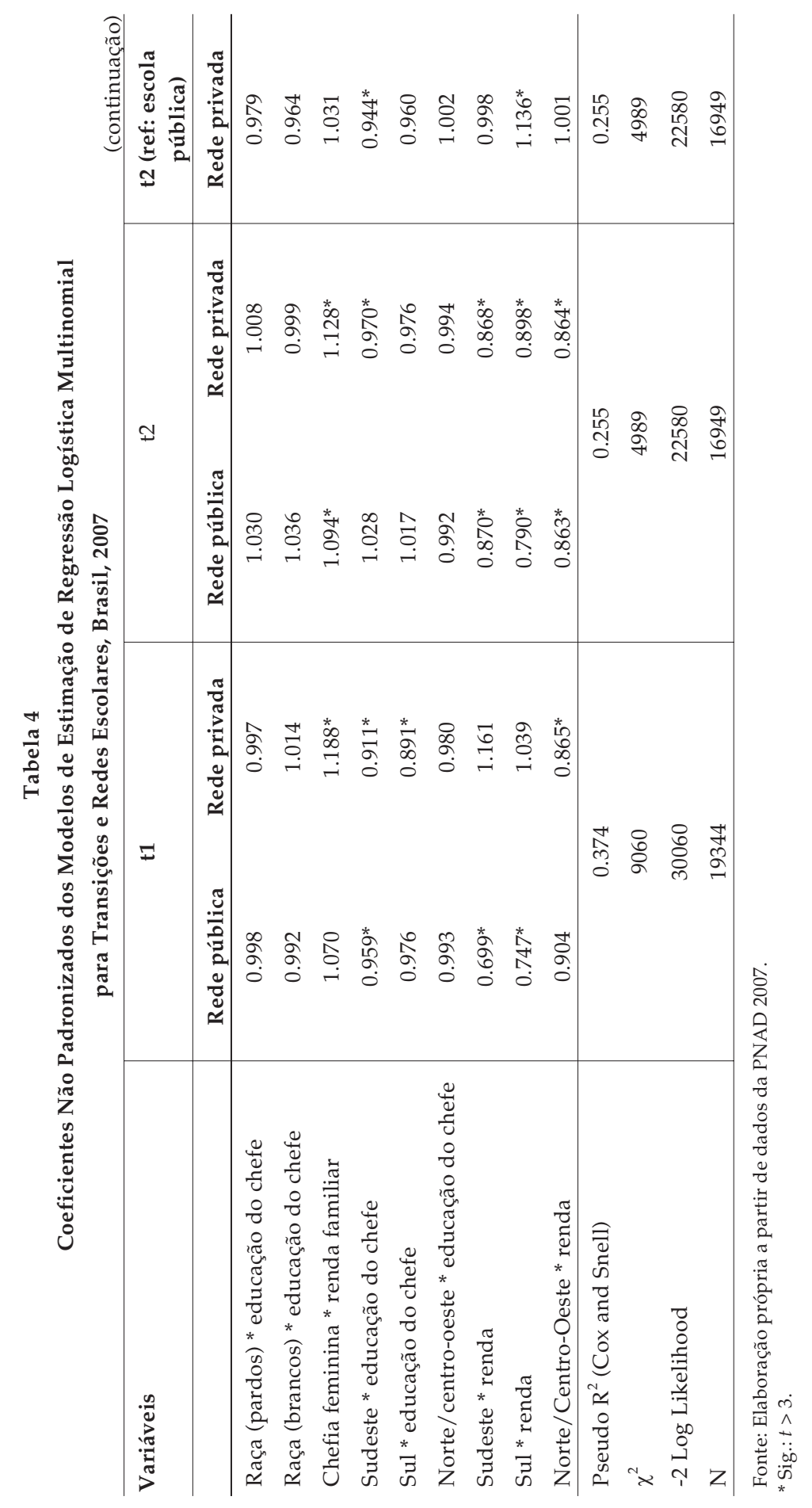


A idade, como esperado, apresenta efeito positivo - e a idade ao quadrado, negativo, o que indica que, quanto mais velho(a) o(a) estudante, entre 17 e 25 anos, maiores as chances de ter completado as transições.

O coeficiente da variável sexo é significante e positivo em todas as transições e anos. Mulheres apresentam mais chances de completar a educação secundária e entrar na universidade, tanto na rede privada quanto na pública, do que homens, em relação a não completar esta transição. Essa probabilidade, todavia, é maior em escolas privadas do que públicas. Ao longo da década, verifica-se um aumento dessa probabilidade em escolas privadas na transição 1, e uma diminuição progressiva na transição 2. Para as escolas públicas observa-se certa constância do efeito. Em relação às diferenças de efeito entre as transições, verifica-se diminuição na rede pública e aumento na rede privada, o que indica que há diminuição do efeito de gênero na transição para a educação superior em relação à educação secundária na rede pública, mas o contrário é válido para a rede privada. No que concerne à probabilidade de se completar a transição 2 numa escola privada em relação a uma pública (última coluna), verifica-se que o efeito do sexo é mais importante nas escolas privadas, rede em que mulheres tendem a completar a transição para o ensino superior com maior vantagem, embora esta esteja diminuindo ao longo da década. Escolas públicas, em geral, são mais igualitárias, ou menos desiguais, no que concerne às relações de gênero.

As variáveis indicadoras de raça, por sua vez, mostram que pardos apresentam vantagens significativas, em relação aos pretos, de acesso ao ensino superior, em 2004 e 2007. Em 2004, essa vantagem é maior na transição para a escola privada, e em 2007 para a rede pública. No entanto, em ambas as redes essa probabilidade declina da casa dos 50\% para próximo de $30 \%$ no último ano da pesquisa. Não há diferença significativa entre pardos e pretos no que diz respeito a completar a transição 2 na rede particular em relação à rede pública.

Há vantagens de brancos na probabilidade de completar as duas transições, em todos os anos, em relação aos negros. No geral, o efeito é muito maior na rede privada do que na pública, em relação a abandonar a escola. Para a transição 1, o efeito declina ao longo dos anos para a rede pública, o que, junto com a ausência de diferenças entre pardos e pretos, pode ser indicativo da diminuição de desigualdades de raça no 
acesso e completude da educação secundária na educação pública. Por outro lado, o efeito aumenta paulatinamente na rede privada, indicando o recrudescimento de desigualdades raciais nesta rede de ensino ao longo da década, em relação àqueles que não completaram a transição. Para a transição 2, verifica-se certa constância do efeito ao longo da década que, todavia, varia entre $90 \%$ e $100 \%$ de vantagem dos brancos em relação aos negros. Mais uma vez, o efeito é maior na rede privada. A diferença entre as transições aponta para o aumento da desigualdade na entrada para a universidade. Brancos, em relação a negros, não apresentam mais probabilidade de acesso à rede particular do que em relação à rede pública neste nível, indicando que os fatores de diferenciação no acesso às diferentes redes de ensino superior são outros.

A educação do chefe apresenta efeito significativo positivo em todos os caminhos analisados: cada ano a mais de escolaridade do chefe da família implica progressivamente maiores chances de se completar o ensino secundário e de se acessar o ensino superior, tanto na rede pública quanto privada, em relação a abandonar o sistema escolar. Na transição 1 o efeito para a rede privada é crescente e torna-se maior que para a rede pública, ou seja, a educação do chefe é mais forte para se completar a transição na escola privada que na pública. Na transição 2 o efeito é semelhante. Na diferença entre as transições, percebe-se que o efeito na segunda é maior que na primeira, permitindo aceitar a hipótese MMI para o caso brasileiro, no que concerne à educação do chefe. Ao longo da década, o efeito da educação do chefe declina um pouco para a rede pública na transição 1 - também sinal de redução de desigualdades pela influência da transmissão de capital cultural -, mas aumenta consideravelmente na rede privada, reforçando desigualdades construídas pela transmissão de capital cultural. Na transição 2 encontramos o mesmo padrão que na transição 1 . No que concerne às chances de se completar a transição 2 na escola privada em relação a completar na rede pública, a educação do chefe também tende a não importar, apesar de em 2007 ser significativa $(2,4 \%)$.

A renda familiar, por sua vez, independentemente do clima educacional do domicílio, apresenta efeito significativo em praticamente todos os caminhos, exceto para a rede pública na transição 1, em todos os anos analisados. Assim, o aumento da educação familiar não faz diferença para se completar o ensino secundário numa escola pública, em relação a não completá-lo. Para a rede privada, por outro lado, o efeito da renda é crescente, indo de 7,4\%, em 2001, a 51,5\%, em 2007. Na tran- 
sição 2 há efeito da renda para se entrar numa universidade pública, efeito também crescente ao longo da década, o que indica aumento das dificuldades para estudantes pobres ingressarem nesta rede de ensino. Todavia, o efeito é ainda maior na rede privada, e também crescente ao longo da década, confirmando a importância da renda para acesso à educação superior paga. Verifica-se, por fim, que a renda é mais importante para se ter acesso à rede privada, em relação à rede pública (coluna 5).

A variável chefia feminina tem, em geral, efeito negativo sobre as chances de se completar as transições - só não há efeito na transição 1 para a rede pública em 2001. Comparando-se o efeito nas duas transições, verifica-se que ele aumenta na escola pública, indicando o peso de uma família quebrada sobre as possibilidades de se ter acesso a uma boa universidade pública, e diminui na privada, abrindo espaço para outros fatores determinantes. Esse padrão para a rede privada condiz com os achados de Lucas (2001) para os EUA. Ao longo da década observa-se aumento do efeito dessa variável nas chances de se completar as transições na rede privada, enquanto na pública esse efeito tende a ser constante. No que diz respeito às chances de acesso à rede privada, em relação à pública, não há efeito significativo.

O número de filhos(as) no domicilio também apresenta efeito negativo: cada filho(a) a mais representa decréscimo nas chances de se completar uma transição, em relação a abandonar a escola, seja na rede privada ou pública, para todos os anos pesquisados, comprovando-se o efeito da composição domiciliar sobre as chances de alcance educacional dos indivíduos (Silva, 2003). Na transição 1, ao longo da década o efeito se torna maior na rede privada - com aumento gradativo - que na pública - com declínio gradativo -, enquanto na transição 2 o efeito é constantemente maior para a rede privada. A tendência geral é de declínio do efeito, em ambas as redes, ao longo da década. Há diferenças significativas de probabilidade de se ter acesso à rede privada em relação à rede pública, a qual cai de $18 \%$ para $10 \%$ a menos de chances de acesso a cada filho a mais.

Áreas urbanas e metropolitanas apresentam efeito positivo para $2004 \mathrm{e}$ 2007 - exceto para a rede pública na transição 2 -, mas não em 2001. Tanto para a transição 1 quanto para a 2 o efeito é maior para a rede privada que para a pública, dada a maior disponibilidade de serviços educacionais de níveis secundário e superior em áreas urbanas e me- 
tropolitanas. Há redução do efeito ao longo das transições para a rede privada, e há diferenças significativas entre a probabilidade de se acessar o ensino superior na rede privada em relação à pública, em áreas urbanas ou metropolitanas, em referência a uma área rural, diferenças que também a presentam tendência de diminuição ao longo da década, provavelmente devido à extensão do ensino pago a distância para pequenas localidades urbanas e áreas rurais próximas nos últimos anos.

No que toca às diferenças regionais, evidencia-se desigualdades acentuadas, principalmente das regiões Sudeste e Sul em relação a Nordeste. O padrão é de crescimento das desigualdades nas possibilidades de se completar as transições, tanto em rede pública quanto em privada, ao longo da década. As diferenças são maiores na transição 1 e na rede privada. As chances de acesso à rede privada, em relação à rede pública, são positivas em todas as regiões em referência ao Nordeste.

A análise dos termos interativos, por sua vez, indica que o aumento da renda para brancos, em relação ao aumento para pretos, tem, em geral, efeito negativo, ou seja, o aumento da renda tem maior efeito para pretos completarem uma transição do que para brancos. Isso é mais acentuado na rede privada, em ambas as transições. Na rede pública não há efeito significativo. Há efeito crescente ao longo da década na rede privada, indicando aumento das chances de se completar a transição para indivíduos de cor preta com maior renda. O aumento da renda para brancos, em relação ao aumento para pretos, não tem efeito significativo no que concerne ao completar a transição 2 na rede privada em referência à rede pública. A interação cor e educação do chefe não apresenta efeito significativo. Também aquelas para pardos (educação do chefe e renda) não apresentam efeito significativo.

O efeito das interações da chefia feminina e a renda familiar é, em geral, positivo - exceto para a rede pública na transição 1, que não apresenta efeito -, o que quer dizer que o aumento da renda possui maior efeito para domicílios que não têm chefia feminina, elevando as chances de se concluir as transições para estudantes nestes domicílios em relação aos que têm chefia feminina.

Os termos interativos para regiões indicam que o aumento da educação do chefe no Sudeste e no Sul, em relação ao Nordeste, apresenta efeito negativo, ou seja, o incremento na educação do chefe implica que indivíduos tenham maior chance de completar as transições no Nordeste que nestas regiões. O efeito do aumento da educação do chefe nas 
chances de se completar a transição na rede privada, em relação à pública, também é negativo, ou seja, o aumento da escolaridade do chefe é mais importante para se completar as transições na rede pública do que na privada, no Nordeste em comparação com Sudeste ou Sul.

A interação das regiões com a renda familiar apresenta tendência parecida: o aumento da renda familiar é mais importante para se completar as transições no Nordeste do que nas outras regiões.

\section{DISCUSSÃO}

Este estudo propõe uma discussão da estratificação educacional no Brasil, na primeira década do século XXI. Tendo como referência várias abordagens teóricas e modelos analíticos que têm desvelado a reprodução das desigualdades sociais por meio da educação ao redor do mundo, propôs-se analisar a influência das origens sociais nas transições educacionais dos estudantes brasileiros para conclusão do ensino médio e acesso ao ensino superior, a partir de modelos que permitissem entender o efeito das origens sociais, assim como de variáveis familiares e espaciais, no alcance educacional de estudantes nos níveis secundário e terciário, na rede pública e privada.

Os resultados indicam, em geral, um quadro de alta desigualdade nas chances de se completar as transições educacionais, tanto na rede pública quanto na rede privada. As variáveis que representam a organização familiar mostram que famílias "quebradas" e aquelas com grande prole, prejudicam o desempenho dos estudantes. Ser membro de uma família quebrada, durante o ensino secundário, diminui drasticamente as chances de se completar essa transição e, consequentemente, de entrar para a universidade.

Diferenças relacionadas ao nível de urbanização indicam que, embora existam desigualdades consideráveis de acesso a serviços de ensino secundário e superior, com vantagem para áreas urbanas e metropolitanas, há diminuição desse efeito no final da década. A expansão dos cursos não presenciais a distância podem estar ajudando neste processo.

Encontrou-se também a permanência das desigualdades regionais, as quais implicam desvantagem de estudantes nordestinos nas possibilidades de se completar as transições analisadas, independente da renda e do nível educacional familiares. Aumentos da renda e da educa- 
ção familiares são, então, mais importantes para estudantes do Nordeste que das outras regiões em geral.

No que concerne às origens sociais, é possível verificar que a hipótese 1 não pode ser rejeitada, ou seja, que o efeito das origens sociais não necessariamente diminui ao longo das coortes, contrariando o que foi proposto pela teoria da modernização. Embora o efeito da educação do chefe diminua levemente nas transições para a escola pública, ele aumenta ou é constante nas transições na rede privada. Na comparação direta entre as redes pública e privada (coluna 5), também se verifica aumento do efeito da educação do chefe na rede privada. O efeito da renda, por sua vez, aumenta marcadamente em todas as transições no período estudado, inclusive na rede privada em relação à rede pública.

Resultados relativos à desigualdade racial também não permitem aceitar a hipótese meritocrática para este contexto. Primeiro, mostram que pardos detêm vantagens em relação aos pretos para acesso à educação superior, seja na rede pública, seja na rede privada. As desigualdades entre brancos e pretos, por sua vez, são enormes, embora apresentem leve declínio ao longo da década. A expansão de políticas públicas que visam à diminuição da desigualdade racial no sistema escolar - como o REUNI e os sistemas de cotas e bônus implantados por várias universidades públicas - podem estar ajudando no declínio das desigualdades nessas transições. Mas a possibilidade de se completar o ensino médio numa escola privada, pela melhor estrutura escolar que proporciona aos estudantes, tem sido um dos mecanismos principais que asseguram vantagens na competição por vagas no curso superior, e é cada vez mais desigual no que diz respeito à relação entre brancos e pretos: a diferença vai de 50 a $88 \%$ num período de seis anos. Estes resultados corroboram o argumento de Soares e Alves (2003:159), que apontam que as diferença entre brancos e pretos "é bem maior do que as mudanças possíveis pela intervenção de políticas escolares".

Estes resultados, em geral, questionam a validade da hipótese meritocrática. Como argumenta Hout (2006), desigualdades educacionais são recorrentes em qualquer lugar do mundo, de forma que estudantes cujos pais são altamente educados e ricos têm vantagens sobre estudantes cujos pais têm menor nível educacional e de recursos em qualquer sociedade, seja em países desenvolvidos ou em desenvolvimento. Dados de Silva (2003) indicam que, apesar da diminuição do efeito da escolaridade do chefe da família ao longo das coortes, houve aumento 
do efeito da renda familiar sobre o alcance educacional entre 1981 e 2006, o que não permitem aceitar a hipótese meritocrática. Fernandes (2005) também argumenta que a hipótese meritocrática não pode ser completamente aceita para o caso brasileiro, pois, em seu estudo, raça e origem urbana aumentam seu efeito. Os processos de industrialização e desenvolvimento econômico não teriam proporcionado a equalização do alcance educacional. Como argumentam Hout e DiPrete (2006) e Goldthorpe (1996), há poucos sinais de que o crescimento econômico, o nível de consumo e a expansão educacional, por si mesmos, tenham conexão com maior igualdade educacional. E assim, a idéia de que as desigualdades em todo o mundo declinariam com o tempo, à medida que as sociedades se modernizassem e os sistemas escolares se tornassem universais, não se concretizou, comprometendo os fundamentos básicos da teoria.

A hipótese 2 também não pode ser rejeitada. O efeito da renda familiar, de inexistente na transição 1 , torna-se altamente positivo na transição 2 para o ensino público - embora para a rede privada essa tendência só seja encontrada para o ano de 2002, havendo, então, diminuição do efeito entre as transições. Assim como no estudo de Breen e Jonsson (2000) e Lucas (2001), a educação dos pais importa mais para a transição para o curso superior que para se completar o ensino secundário. $\mathrm{O}$ capital cultural familiar é decisivo no processo de alcance, de forma que indivíduos oriundos de famílias com maior volume desse capital tendem a conquistar maior alcance educacional. Nesse sentido, mostra-se improvável que o efeito das origens socioeconômicas sobre o alcance educacional diminua mesmo em termos de alto desenvolvimento econômico, já que a desigualdade de capital é crucial para o processo de estratificação educacional.

O padrão de expansão educacional brasileiro pode ser então entendido no âmbito do que Shavit e Blossfeld (1993) entendem como padrão universal de políticas de expansão educacional: os sistemas se abrem passo a passo, da base para cima. Coortes vão sucessivamente avançando pequenos passos dentro da hierarquia educacional. Contudo, os maiores níveis educacionais permanecem razoavelmente exclusivos. Verdadeiros gargalos são criados na transição para o nível superior, os quais não acompanham o crescimento dos níveis básicos de ensino, e acabam privilegiando o acesso daqueles oriundos de grupos socioeconomicamente bem-sucedidos. Tal padrão é coerente com as proposições da teoria da reprodução (Bourdieu e Passeron, 1977) - a qual, embo- 
ra não discuta tendências ao longo das transições educacionais, mostra que o capital cultural é o mais importante determinante da persistência da desigualdade escolar -, e com a desigualdade maximamente manti$d a$ (Raftery e Hout, 1993). As proposições da abordagem do ciclo de vida, por sua vez, não encontram respaldo nos dados. Os resultados também não correspondem aos do modelo de seletividade diferencial (Mare, 1980, 1981), que apresenta efeito praticamente inexistente das origens na transição para o ensino superior.

Um processo de permanente racionamento das credenciais mais altas restringe a quantidade de candidatos às posições de privilégio na hierarquia social, mantendo e legitimando desigualdades no alcance escolar. O caso brasileiro, como discutiu Schwartzman (1988), apresenta sérias dificuldades no que diz respeito à equalização das oportunidades sociais, uma vez que as questões centrais estabelecidas pela organização da educação no Brasil, em vez de serem aquelas relacionadas a acesso, equidade, qualidade da educação e desenvolvimento de pesquisa, são as relacionadas a autonomia, governança e diferenciação, questões políticas que relegam para segundo plano a diminuição das desigualdades no alcance escolar.

Por fim, a hipótese 3 só pode ser parcialmente aceita. A hipótese da desigualdade efetivamente mantida aponta a existência de caminhos alternativos, dentro dos mesmos níveis escolares, pelos quais classes sociais procuram reforçar suas vantagens na competição pelas posições mais privilegiadas. Os resultados da renda na transição 1 - ausência de efeito na escola pública e efeito significativo na rede privada - conformam o padrão da EMI, pois estudar nesta rede no ensino médio se traduz em grandes vantagens na competição por vagas nas universidades. Por outro lado, o efeito na transição 2, assim como o da educação dos pais para ambas as transições, embora seja levemente superior na rede privada, é altamente significativo para as duas redes. E como argumenta o propositor da hipótese (Lucas, 2009), a EMI não se preocupa estritamente com o tamanho do coeficiente de efeito das origens sociais, mas, sim, com a forma pela qual as origens proporcionam que estudantes assegurem os caminhos mais valorizados do sistema educacional. No caso da transição para a universidade, os coeficientes das origens revelam que estratos socioeconômicos mais altos da população não asseguram necessariamente um caminho específico, mas praticamente monopolizam o acesso à educação superior, seja na rede pública - a de maior prestígio e que proporcionará maiores retornos ocu- 
pacionais -, seja na privada. Esta análise aponta um alto grau de desigualdade no acesso à educação superior, mas que não necessariamente se conforma aos pressupostos da hipótese EMI.

Os resultados apresentados indicam que a rede privada é mais desigual que a pública. Todavia, embora a escola pública seja mais democrática - o que se comprova pelos efeitos mais baixos das origens sociais, raça, gênero e região em relação à rede privada -, o efeito das origens sociais nesta rede é constante, ou mesmo crescente ao longo do período analisado, apontando uma tendência de recrudescimento da estratificação educacional na rede pública.

A estabilidade das desigualdades educacionais tem consequências para a mobilidade social e para a estratificação da sociedade. Silva (1999) aponta para uma "acentuada estabilidade" nos padrões de mobilidade social no Brasil, pois, embora possa ser detectado um pequeno aumento na mobilidade total no Brasil, liderada pelo aumento da mobilidade circular, a estrutura básica da estratificação da sociedade permanece praticamente inalterada, com grandes classes isoladas umas das outras. Ribeiro (2003) também aponta que, apesar da pequena diminuição de desigualdades das condições de vida, verifica-se uma continuidade das proporções de desigualdades de renda e educação superior na estrutura de classes, que tem mudado muito lentamente, não havendo nenhuma grande mudança na estrutura da estratificação social do país nas últimas décadas.

A transmissão de desigualdades, mediada pela influência das origens sociais nas possibilidades de alcance educacional, contraria, então, o otimismo das teorias da modernização e industrialização. O conjunto desses resultados recentes mostra, em certo sentido, o que Sorokin (1964) já havia percebido há quase um século: quando desaparece ou diminui o efeito de um mecanismo de reprodução social, em vez de um processo de equalização tem-se, outrossim, o surgimento ou intensificação de outro mecanismo que recrudesce as desigualdades sociais.

(Recebido para publicação em abril de 2011)

(Versão definitiva em agosto de 2011) 


\section{Arnaldo Mont'Alvão}

\section{NOTAS}

1. Outras quatro proposições são estabelecidas por Treiman (1970), mas estas fogem ao escopo deste trabalho, pois dizem respeito à associação entre origem social, taxas de mobilidade social e renda.

2. Os treze países analisados na coletânea são Alemanha, Inglaterra e País de Gales, Suíça, Hungria, Polônia, Israel, EUA, Itália, Taiwan, Japão e Tchecoslováquia, Holanda e Suécia.

3. Cameron e Heckman (1998) sugerem outra solução para a questão da heterogeneidade, rejeitando o modelo de transições por este não utilizar variáveis que variem com o tempo. Propõem, então, um modelo de escolha discreta ordenada com heterocedasticidade multiplicativa, cuja variável dependente volta a ser anos completos de escolaridade, sendo introduzidas variáveis independentes que variem com o tempo para melhor interpretar a variação do efeito das origens ao longo transições.

4. Indivíduos que se autoclassificaram como amarelos e indígenas representam menos de $1 \%$ da amostra, tendo sido, por isso, excluídos da analise.

5. As tabelas com as estatísticas descritivas - incluindo valores mínimo e máximo, média e desvio-padrão - assim como aquelas com as correlações entre as variáveis podem ser disponibilizadas pelo autor em caso de interesse.

6. Powers e Xie (2000) não recomendam o uso dos pseudo- $R^{2}$ oferecidos pelos pacotes estatísticos para análise do ajuste de modelos logísticos, tais como o Cox \& Snell e o Nagelkerke, pois estes não seriam tão precisos. Recomendam que se use apenas o qui-quadrado como fonte de análise do ajuste. Entretanto, optou-se aqui por introduzi-los como referência para se poder comparar os resultados com os obtidos por outros trabalhos.

7. Razões de chance maiores que 1 indicam efeito positivo, enquanto as menores que 1 indicam efeito negativo, e as iguais a 1 indicam ausência de efeito. 


\section{Estratificação Educacional no Brasil do Século XXI}

\section{REFERÊNCIAS BIBLIOGRÁFICAS}

AYALON, Hanna; GRODSKY, Eric; GAMORAN, Adam e YOGEV, Abraham. (2008), “Diversification and Inequality in Higher Education: a Comparison of Israel and the United States". Sociology of Education, vol. 81, pp. 211-241.

AYALON, Hanna e SHAVIT, Yossi. (2004), "Educational Reforms and Inequalities in Israel: the MMI Hypothesis Revisited". Sociology of Education, vol. 77, pp. 103-120.

BOUDON, Raymond. (1974), Education, Opportunity and Social Inequality. New York, Willey.

BOURDIEU, Pierre e PASSERON, Jean-Claude. (1977), Reproduction in Education, Society and Culture. London, Sage.

BOWLES, Samuel e GINTIS, Herbert. (1976), Schooling in Capitalist America. New York, Basic Books.

BREEN, Richard e JONSSON, Jan O. (2000), “Analyzing Educational Careers: A Multinomial Transition Model”. American Sociological Review, vol. 65, no 5, pp. 754-772.

CAMERON, Stephen V. e HECKMAN, James J. (1998), “Life Cycle Schooling and Dynamic Selection Bias: Models and Evidence for Five Cohorts of American Males". Journal of Political Economy, vol. 106, pp. 262-333.

CASTRO, Claudio M. (2006), “Educação no Brasil: Atrasos, Conquistas e Desafios”, in Brasil: O Estado de uma Nação. Brasília, IPEA.

CASTRO, Maria H. G. (1998), Avaliação do Sistema Educacional Brasileiro: Tendências e Perspectivas. Brasília, Instituto Nacional de Estudos e Pesquisas Educacionais.

CURY, Carlos R. J. (2002), “A Educação Básica no Brasil”. Educação e Sociedade, vol. 23, pp. 168-200.

DAVIS, Kingsley e MOORE, Wilbert E. (1945), "Some Principles of Stratification". American Sociological Review, vol. 10, pp. 242-249.

FERNANDES, Danielle C. (2005), "Race, Socioeconomic Development and the Education Stratification Process in Brazil". Research in Social Stratification and Mobility, vol. 22, pp. 365-422.

GERBER, Theodore. (2000), “Educational Stratification in Contemporary Russia: Stability and Change in the Face of Economic and Institutional Crisis". Sociology of Education, vol. 73, no 4, pp. 219-246.

; HOUT, Michael. (1995), "Educational Stratification in Russia during the Soviet Period". American Journal of Sociology, vol. 101, pp. 611-660.

GOLDTHORPE, John. H. (1996), “Class Analysis and the Reorientation of Class Theory: The Case of Persisting Differentials in Educational Attainment". The British Journal of Sociology, vol. 47, no 3, pp. 481-505.

HASENBALG, Carlos; SILVA, Nelson do Vale. (1990), "Raça e Oportunidades Educacionais no Brasil". Cadernos de Pesquisa, vol. 73, pp. 5-12.

HAUSER, Robert M. e FEATHERMAN, David L. (1976), “Equality of Schooling: Trends and Prospects". Sociology of Education, vol. 49, no 2, pp. 99-120. 


\section{Arnaldo Mont'Alvão}

. (1978). Opportunity and Change. New York, Academic Press.

HEYNS, Barbara e BIALECI, Ireneusz. (1993), "Educational Inequalities in Postwar Poland", in Y. Shavit e H. Blossfeld, Persistent Inequality: Changing Educational Attainment in Thirteen Countries. Boulder/San Francisco/Oxford, Westview Press, pp. 303-336.

HOUT, Michael. (2006), “Maximally Maintained Inequality and Essentially Maintained Inequality: Crossnational Comparisons". Sociological Theory and Methods, vol. 21, no 2, pp. 237-252.

e DIPRETE, Thomas A. (2006), “What We Have Learned: RC28's Contributions to Knowledge about Social Stratification". Research in Social Stratification and Mobility, vol. 24, pp. 1-20.

INSTITUTO NACIONAL DE ESTUDOS E PESQUISAS EDUCACIONAIS. (2006), Levantamento Estatístico sobre o Ensino Médio e Educação Superior. Brasília, INEP.

KAREN, David. (2002), "Changes in Access to Higher Education in the United States: 1980-1992". Sociology of Education, vol. 75, no 3, pp. 191-205.

LENSKI, Gerhard E. (1966), Power and Privilege: A Theory of Social Stratification. New York, McGraw Hill.

LUCAS, Samuel R. (2001), “Effectively Maintained Inequality: Education Transitions, Track Mobility and Social Background Effects". The American Journal of Sociology, vol. 106, no 6, pp. 1642-1690.

(2009), "Stratification Theory, Economic Background, and Educational Attainment: A Formal Analysis". Rationality and Society, vol. 21, pp. 459-511.

MARE, Robert D. (1980), “Social Background and School Continuation

Decisions". Journal of the American Statistical Association, vol. 75, pp. 295-305.

. (1981), “Change and Stability in Educational Stratification". American Sociological Review, vol. 46, no 1, pp. 72-87.

. (1994), “Discrete-Time Bivariate Hazards with Unobserved Heterogeneity: a Partially Observed Contingency Table Approach". Sociological Methodology, vol. 24, pp. 341-383.

MARTINS, Carlos B. (2000), “O Ensino Superior Brasileiro nos Anos 90”. São Paulo em Perspectiva, vol. 14, no 1, pp. 41-60.

MINISTÉRIO DA EDUCAÇÃO. (2002), “Breve Evolução História do Sistema Educacional Brasileiro", in Organização dos Estados Ibero-Americanos, Sistema Educativo Nacional do Brasil. Disponível em http://www.oei.es/quipu/brasil/index.html\#eval. Acessado em 28/9/2010.

MULLER, Walter e KARLE, Wolfgang. (1993), “Social Selection in Educational Systems in Europe". European Sociological Review, vol. 9, no 1, pp. 1-23.

PARSONS, Talcott. (1970), “Equality and Inequality in Modern Society, or Social Stratification Revised", in E. O. Laumann (ed.), Social Stratification: Research and Theory for the 1970s. Indianapolis, Bobbs-Merril, pp. 13-72.

POWERS, Daniel e XIE, Yu. (2000), Statistical Methods for Categorical Data Analysis. San Diego/London, Academic. 


\section{Estratificação Educacional no Brasil do Século XXI}

RAFTERY, Adrian E. e HOUT, Michael. (1993), “Maximally Maintained Inequality: Expansion, Reform, and Opportunity in Irish Education, 1921-1975". Sociology of Education, vol. 66, no 1, pp. 41-62.

RIBEIRO, Carlos A. C. (2003), “Estrutura de Classes, Condições de Vida e Oportunidades de Mobilidade Social no Brasil", in N. do V. Silva e C. Hasenbalg (eds.), Origens e Destinos: Desigualdades Sociais ao Longo da Vida. Rio de Janeiro, Topbooks, pp. 381-430.

SCHWARTZMAN, Simon. (1988), “Brazil: Opportunity and Crisis in Higher Education". Higher Education, vol. 17, no 1, pp. 99-119.

SHAVIT, Yossi e BLOSSFELD, Hans-Peter. (1993), Persistent Inequality: a Comparative Study of Educational Attainment in Thirteen Countries. Boulder/San Francisco/Oxford, Westview Press.

SILVA, Nelson do V. (1999), "Vinte e Três Anos de Mobilidade Social no Brasil". Teoria \& Sociedade, vol. 4, p. 181-211.

. (2003), "Expansão Escolar e Estratificação Educacional no Brasil", in N. do V. Silva e C. Hasenbalg (eds.), Origens e Destinos: Desigualdades Sociais ao Longo da Vida. Rio de Janeiro, Topbooks, pp. 105-138.

e HASENBALG, Carlos. (2000), “Tendências da Desigualdade Educacional no Brasil". DADOS, vol. 43, no 3, pp. 423-445.

; MELLO E SOUZA, Alberto de e RODITI, Déborah. (1985), “Industrialização e Desigualdades Educacionais no Brasil". Rio de Janeiro, Laboratório Nacional de Computação Científica, Relatório de Pesquisa e Desenvolvimento 002/85.

SOARES, José F. e ALVES, Maria T. G. (2003), “Desigualdades Raciais no Sistema Brasileiro de Educação Básica". Educação e Pesquisa, vol. 29, no 1, pp. 147-165.

SOROKIN, Pitirim A. (1964), Social and Cultural Mobility. Glenonce, Free Press.

SPADY, William G. (1967), "Educational Mobility and Access: Growth and Paradoxes". The American Journal of Sociology, vol. 73, no 3, pp. 273-286.

SZELENYI, Szonja e ASCHAFFENBURG, Karen. (1993), "Inequalities of Educational Opportunity in Hungary", in Y. Shavit e H. Blossfeld, Persistent Inequality: Changing Educational Attainment in Thirteen Countries. Boulder/San Francisco/Oxford, Westview Press, pp. 273-302.

TORCHE, Florencia. (2010), “Economic Crisis and Inequality of Educational Opportunity in Latin America". Sociology of Education, vol. 83, no 2, pp. 85-110.

TREIMAN, Donald J. (1970), "Industrialization and Social Stratification", in E. O. Laumann, Social Stratification: Research and Theory for the 1970s. Indianapolis, Bobbs-Merrill, pp. 207-234.

; GANZEBOOM, Harry B. e RIJKEN, Susanne. (2003), “Educational Expansion and Educational Achievement in Comparative Perspective". On-line working paper series - California Center for Population Research. University of California. Disponível em http:/ / escholarship.org/uc/item/2mc7c70q. Acessado em 21/9/2010.

WONG, Raymond S-K. (1998), “Multidimensional Influences of Family Environment in Education: the Case of Socialist Czechoslovakia". Sociology of Education, vol. 70, pp. $1-22$.

ZHOU, Xueguang; MOEN, Phyllis e TUMA, Nancy B. (1998), “Educational Stratification in Urban China: 1949-1994". Sociology of Education, vol. 71, no 3, pp. 199-222. 


\section{ABSTRACT \\ Educational Stratification in $21^{\text {st }}$ Century Brazil}

This article focuses on educational stratification in Brazil in the first decade of the $21^{\text {st }}$ century. It discusses the main approaches and empirical models for the theme in Brazil and the world in general. With effectively maintained inequality as the principal reference, the study tests hypotheses for the Brazilian case using multinomial logistic regression models that analyze the odds of finishing secondary school and entering the university (government or private), based on data from the National Household Sample Surveys (PNADs) for the years 2001,2004, and 2007. The main results point to the persistence or even increase in the impact of social origins on access to higher education as compared to secondary school, in addition to the recrudescence of such inequalities in the early $21^{\text {st }}$ century. Although the private university system is more unequal than the public system, the latter has shown a considerable increase in educational stratification. Inequalities based on geographic region, race, gender, and social capital are also present.

Key words: educational stratification; school transition; public system; private system: Brazil

\section{RÉSUMÉ}

\section{Stratification dans l'Éducation Brésilienne du XXIe Siècle}

Dans cet article, on examine le processus de stratification dans l'éducation brésilienne pendant la première décennie de notre siècle. On y étudie les principales approches et les modèles empiriques qui sont consacrés à ce sujet non seulement dans le pays mais aussi dans le monde. En prenant comme référence principale l'hypothèse de l'inégalité effectivement conservée, on a testé des hypothèses sur le cas brésilien à travers des modèles de régression logistique multinomiale qui analysent les chances d'achever l'enseignement secondaire et d'entrer à l'université, dans les services de scolarité publique et privée, à partir des données des PNAD (Sondage National par Echantillonnage à Domicile) concernant les années 2001, 2004 et 2007. Les principaux résultats montrent le maintien ou même l'augmentation de l'influence de l'origine sociale dans l'accès à l'éducation supérieure par rapport à l'enseignement secondaire, ainsi que l'accentuation des inégalités tout au long de cette décennie. Bien que l'école privée soit plus inégale que l'école publique, celle-ci présente un accroissement considérable de la stratification dans l'éducation. On remarque aussi des inégalités de régions, races, genre et capital social.

Mots-clés: stratification dans l'éducation; transitions scolaires; école publique; école privée; Brésil 